\title{
3D printing of biomedically relevant polymer materials and biocompatibility
}

\begin{abstract}
Joseph Rey H. Sta. Agueda, Department of Macromolecular Science and Engineering, Case Western Reserve University, Cleveland, OH 44106, USA; Department of Manufacturing Engineering and Management, De La Salle University, 1004 Manila, Philippines; Department of Chemical Engineering, De La Salle University, 1004 Manila, Philippines

Qiyi Chen, Department of Macromolecular Science and Engineering, Case Western Reserve University, Cleveland, OH 44106, USA; Center for Nanophase Materials and Sciences, Oak Ridge National Laboratory, Oak Ridge, TN 37830, USA

Reymark D. Maalihan, Department of Macromolecular Science and Engineering, Case Western Reserve University, Cleveland, OH 44106, USA; Department of Chemical and Food Engineering and Material Testing and Calibration Center, Batangas State University, 4200 Batangas City, Philippines

Jingbo Ren, Department of Macromolecular Science and Engineering, Case Western Reserve University, Cleveland, OH 44106, USA

Ítalo G. M. da Silva, Department of Macromolecular Science and Engineering, Case Western Reserve University, Cleveland, OH 44106, USA; Escola de Química, Universidade Federal do Rio de Janeiro, Rio de Janeiro, RJ 21941-909, Brazil

Nathaniel P. Dugos, Department of Chemical Engineering, De La Salle University, 1004 Manila, Philippines

Eugene B. Caldona, Department of Macromolecular Science and Engineering, Case Western Reserve University, Cleveland, OH 44106, USA; Department of Chemical and Biomolecular Engineering and Joint Institute for Advanced Materials, University of Tennessee, Knoxville, TN 37996, USA

Rigoberto C. Advincula, Department of Macromolecular Science and Engineering, Case Western Reserve University, Cleveland, OH 44106, USA; Department of Chemical and Biomolecular Engineering and Joint Institute for Advanced Materials, University of Tennessee, Knoxville, TN 37996, USA; Center for Nanophase Materials and Sciences, Oak Ridge National Laboratory, Oak Ridge, TN 37830, USA
\end{abstract}

Address all correspondence to Rigoberto C. Advincula at radvincu@utk.edu

Rigoberto C. Advincula was an editor of this journal during the review and decision stage. For the MRS Communications policy on review and publication of manuscripts authored by editors, please refer to http://www.mrs.org/editor-manuscripts/.

(Received 2 February 2021; accepted 8 April 2021; published online 26 April 2021)

\section{Abstract}

Research on polymer materials for additive manufacturing technology in biomedical applications is as promising as it is numerous, but biocompatibility of printable materials still remains a big challenge. Changes occurring during the 3D-printing processes itself may have adverse effects on the compatibility of the completed print. This prospective will put emphasis on the different additives and processes that can have a direct impact on biocompatibility during and after 3D printing of polymer materials.

\section{Introduction}

The inclusion of additive manufacturing (AM) technologies in biomedical research has brought considerable advancement in healthcare technology. With advances in tissue engineering, damaged tissues can now be repaired and replaced by scaffolds manufactured from biocompatible materials, which allow cells to grow into new and healthy tissues. ${ }^{[1]}$ Partnered with current imaging technologies, 3D printing aids in the creation of intricate scaffold designs that mimic the shape and form of what is found in the human body. ${ }^{[2]}$ The capacity to design scaffolds at the microarchitecture level leads to better response in cell growth, while the ability to alter porosity enables control over cell migration and adhesion. ${ }^{[3]} 3 \mathrm{D}$ printing, combined with tissue engineering, brings regenerative medicine the promise of repairing or replacing damaged tissues or even organs with cell-laden constructs much closer to proper function in the human body. ${ }^{[4]}$

3D-printed structures used in the different parts of the human body also present varying challenges and potential.
Every intended application comes with a different set of specifications that greatly affect the choice of both material and printing method. They are further classified as resorbable and non-resorbable as implants, that is, meant to degrade or not to degrade, respectively. Alginate hydrogels, for example, have the appropriate gelation times required in 3D printing, but have been found to possess undesirable degradation properties in vivo, while other more biodegradable polymers could be made to achieve correct gelation times through ultraviolet (UV) crosslinking. ${ }^{[5]}$ Nowadays, a combination of covalent crosslinking and photo-initiated crosslinking is used to create better performing hydrogels that are gradient degradable. ${ }^{[6]}$ \{Skardal, 2015, A hydrogel bioink toolkit for mimicking native tissue biochemical and mechanical properties in bioprinted tissue constructs $\}$.

There are six criteria for 3D-printing biomaterials. The material should exhibit the following properties: (1) printability, (2) biocompatibility, (3) desirable mechanical properties, (4) biodegradability, (5) no hazardous by-products, and (6) 
mimicking natural tissue architecture. ${ }^{[2]}$ Although the potential printability of a material has a significant effect on whether it would be a good candidate for 3D printing in the first place, all of the aforementioned criteria are equally as important.

In this prospective and review, the current development of 3D printing of biomedically relevant and biocompatible polymers is discussed. First, different types of biocompatible materials are introduced, followed by different 3D printing techniques and their utility in biocompatible material fabrications. The processing conditions including curing process, UV exposure, heat exposure, etc. influencing the properties of biocompatible materials are also discussed. Finally, the testing method of the biocompatible materials is covered. A prospective on the promise of biocompatible polymers, hybrid materials, and new applications is also discussed at the end.

\section{Biocompatible and biomedical materials}

Biocompatible materials, used for 3D printing biomedically relevant parts/components, are easily categorized into natural polymers, synthetic polymers, and ceramics. ${ }^{[7]}$ Other classes of materials include metals, alloys, and hybrid materials or composites, although these are not covered in this review. Biocompatible materials have to be absolutely non-cytotoxic and should biodegrade into components that the body can easily get rid of, while maintaining a healthy immune response even after they are implanted ${ }^{[8]}$ The biocompatibility of medical devices is discussed thoroughly in ISO 10993, a document detailing the measurement and establishment of biocompatibility. Biodegradation kinetics needs to be fine-tuned in the materials used. If the implanted material is to degrade rapidly, the healing site could suffer collapse, while a material that remains intact for a long period can trigger an inflammatory response. ${ }^{[9]}$

Biomaterials as a class of materials have improved drastically over time. The first materials (e.g., stainless steel) to be considered in the surgical setting were chosen due to the suitability of their mechanical properties for the intended use, while causing the least possibility of rejection and non-degradation.
The next generation of materials (e.g., titanium and collagen) displayed little bio-corrosivity or is imbibed with bioactive properties such as favorable tissue integration and controlled degradation. Going beyond bioactive properties, the newest crop of biocompatible materials possess bioinductive properties, meaning not only are the materials compatible with tissues, but also support healing with improved healing conditions. ${ }^{[10]}$ Again, the main focus of this review is on polymer materials and they can be discussed using the classification below.

\section{Natural polymers}

Bioactive natural polymers have excellent performance in supporting cellular adhesion and proliferation. These types of polymers have also been found to be exceptional scaffold building materials due in large part to their ability to support the formation of new extra cellular matrix upon degradation. There are also traces of both functional and structural molecules in natural polymers that lead to improved cell growth. The natural polymers can be classified as polysaccharides, polypeptides, polynucleotides, glycoproteins, and others include collagen (and components of the extracellular matrix or ECM). While a review of the many classes is possible, here are a few specific examples:

\section{Silk fibroin}

Silk fibroin [Fig. 1(a)], a natural biopolymer and fibrous protein produced by Bombyx mori, Antheraea mylitta, and other moth and spider genera, ${ }^{[11,12]}$ has been widely studied in the field of tissue engineering due to its biocompatibility, low adverse reaction of immune system, and degradability in vivo thru naturally occurring proteolitic enzymes. ${ }^{[13,14]}$ Silk fibroin scaffolds can be produced in different ways including freeze-drying, ${ }^{[15]}$ electrospinning, ${ }^{[16]}$ and 3D bioprinting. ${ }^{[17]}$ It has been used to produce tissue constructs such as skin, ${ }^{[18]}$ urethra, ${ }^{[19]}$ retina, ${ }^{[20]}$ blood vessel, ${ }^{[21]}$ cardiac tissue,${ }^{[16]}$ bone, ${ }^{[17]}$ and cartilage,,${ }^{[22]}$ to name a few. Silk fibroin can also render human cells such as mesenchymal stem cells (MSCs) ${ }^{[23]}$ epithelial cells, glial cells, keratinocytes, fibroblasts, and osteoblast cells ${ }^{[14]}$ to adhere and proliferate throughout the scaffold. (a)<smiles>CCNC(=O)CNC(=O)C(C)NC(=O)CNC(=O)C(C)NC(=O)CNC(=O)C(CO)NC(=O)CNC(=O)C(C)NC(=O)CNC(=O)C(C)NC(=O)CNC(=O)C(C)NC(=O)CNC(=O)C(CO)NC(=O)CNC(=O)C(CO)NC(C)(C)C</smiles>

(b)
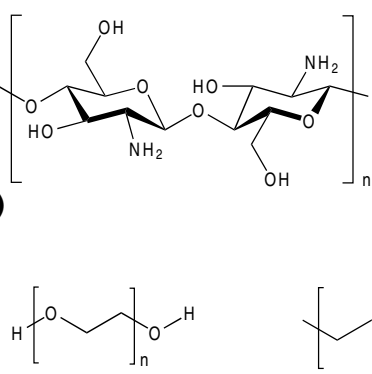

(d)

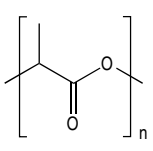

(c)

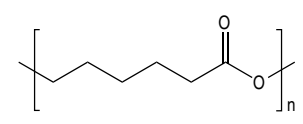

(e)

Figure 1. (a) The amino acid repeating unit structure of silk fibroin. Chemical structures of (b) chitosan, (c) PLA, (d) PEG, and (e) PCL. 


\section{Chitosan}

Chitosan [Fig. 1(b)], a linear polysaccharide and well-known organic biopolymer derived from partially deacetylated chitin, a core component of an exoskeleton of crustaceans like crabs, has been employed in various biomedical applications such as wound dressing, drug delivery, and tissue engineering. ${ }^{\text {[24-27] }}$ Chitosan is particularly an appealing biomaterial for tissue engineering due to its abundance, biorenewability, biocompatibility, biodegradability, non-toxicity, and predominantly hydrophilicity. ${ }^{[24,27]}$ Due to its hypoallergenic property, antibacterial activity, and ability to quickly clot blood, chitosan has been useful in bandages, gauze dressings, and hemostatic agents. ${ }^{[28]}$ Because of its reactivity, mucoadhesive property, insolubility in basic and neutral solutions, and ability to be protonated, chitosan is also useful in drug delivery (e.g., insulin transport) in acidic environment, where it biodegrades and allows the drug to be released. ${ }^{[28]}$ Chitosan-based scaffolds have been fabricated in various methods such as freeze-drying, ${ }^{[29]}$ electrospinning, ${ }^{[30]}$ and 3D bioprinting. ${ }^{[31]}$ Their hydrophilic nature also makes them a viable material for cryogel and hydrogel. ${ }^{[31,32]}$ The use of chitosan-based scaffolds has shown positive results mostly in bone tissue engineering, ${ }^{[33-35]}$ cardiovascular tissues, ${ }^{[36,37]}$ cartilage, ${ }^{[29]}$ skin, ${ }^{[38]}$ and neural tissue. ${ }^{[39]}$ Chitosan is also promising in fabricating artificial kidney membranes due to its mechanical integrity and permeability. ${ }^{[28]}$

\section{Synthetic polymers}

Synthetic polymers display desirable characteristics for printability and are easily printed into complex architectures. However, most of these polymers degrade via hydrolysis, causing an acidic environment to form at the site of implantation leads to necrosis of the surrounding tissue. They can be classified as polycondensation polymers, polyolefinic, vinyl polymers, and high performance polymers (high melting point and composites). ${ }^{[40]}$ They can also be classified as bio-based, bio-derived, or modified synthetic polymers. Again, a review of synthetic polymers is possible, but a number of examples are described below.

\section{Polylactic acid}

Polylactic acid [PLA, Fig. 1(c)] or polylactide is a synthetic aliphatic polyester commonly derived from plant starches (corn, sugar beet, wheat, etc.). It is one of the most widely used polymers due to its biodegradability, bioresorbability, solubility in various organic solvents, and processability. ${ }^{[41]}$ PLA has been used in many applications such as wound treatment, ${ }^{[42]}$ drug delivery, ${ }^{[43]}$ and scaffold fabrication. ${ }^{[44]}$ PLA scaffold fabrication can be done using various methods such as electrospinning ${ }^{[45]}$ and $3 \mathrm{D}$ bioprinting, ${ }^{[46]}$ and the scaffolds have been proven to be suitable proliferation sites for various cells such as osteoblasts, ${ }^{[44,47]}$ adipose derived stem cells, ${ }^{[46]}$ and MSCs. ${ }^{[48]}$ It is also one of the most widely 3D-printed polymer by fused deposition modeling (FDM). Due to its biodegradability into non-toxic lactic acid, PLA can be 3D printed into pins, mesh, and screws for utility as biomedical implants. ${ }^{[28]}$

\section{Polyethylene glycol}

Polyethylene glycol (PEG), a type of synthetic hydrophilic polymer, is used in various biomedical applications such as drug delivery, tissue engineering, and surface modification. ${ }^{\text {[4-52] }}$ It is composed of a linear and branched, neutral polyether [Fig. 1(d)] that is soluble in water and most organic solvents such as methanol, toluene, and benzene. ${ }^{[53]}$ PEG hydrogels are among the most widely used and studied polymeric materials for biomedical applications, because of their biocompatibility, low toxicity, and non-immunogenicity. ${ }^{[54]}$ PEG hydrogels and its derivatives are commonly chemically modified or crosslinked with other biocompatible hydrogel materials and these have also been utilized in $3 \mathrm{D}$ bioprinting of scaffolds. ${ }^{[55]}$ In fabricating scaffolds for tissue engineering, PEG has been crosslinked with a number of synthetic polymers such as PLA, ${ }^{[56]}$ polycaprolactone $(\mathrm{PCL}),{ }^{[57]}$ chitosan and PEG acrylates including PEG dimethacrylate (PEGDMA), PEG diacrylate (PEGDA), and multiarm PEG (n-PEG) acrylate (n-PEG-Acr). ${ }^{[58-61]}$ PEG-based hydrogels have had promising results in constructing scaffolds for bone, ${ }^{[57,62,63]}$ cartilage ${ }^{[55,61]}$ and vascular tissues. ${ }^{[64,65]}$ They are widely $3 \mathrm{D}$-printed with acrylate telechelic groups or using blends with acrylate type resins via stereolithographic apparatus (SLA) or digital light projection (DLP). In addition, a PEG hydrogel can be transformed from being a rigid to flexible material by increasing its central segment's molecular weight. Inclusion of chemical groups such as lactate or glycolate can optimize its biodegradation and bioabsorption rates. ${ }^{[28]}$

\section{Polycaprolactone}

Polycaprolactone [PCL, Fig. 1(e)] is a biodegradable polyester created from the ring opening polymerization of $\epsilon$-caprolactone. ${ }^{[66]}$ PCL-based scaffolds have mechanical properties that exhibit similar trends to native scaffolds. ${ }^{[67]}$ In general, PCL is a promising implantable biomaterial as it can be biodegraded by physiologically hydrolyzing its ester linkage. ${ }^{[28]}$ Due to its hydrophobicity and crystallinity, PCL as a standalone polymer has a very slow degradation rate (even slower than that of PLA), which makes it ideal for fabricating long-term implantable materials. ${ }^{[68]}$ It is used as a hydrophobic block in forming vesicle membranes of polymersomes. PCL is also synthesized alongside other polymers to lower its cost and accelerate its rate of degradation and bioabsorption for other purposes. ${ }^{[69]}$ PCL scaffolds, for use in tissue repair and bone regeneration membrane, are manufactured using various means such as electrospinning ${ }^{[70]}$ and BioCell printing, to name a few. ${ }^{[71]}$ The scaffolds have shown promising results when used in various applications such as those in bone, ${ }^{[72]}$ vascular, ${ }^{[73]}$ and nerve tissues. ${ }^{[74]}$ This polymer can be easily 
printed using FDM and selective laser sintering (SLS). PCL, under the brand name Monocryl, has been approved by the Food and Drug Administration (FDA) for biomedical use, particularly in drug delivery. Under the composite named Resilon, PCL is used in dentistry as a dental splint and root canal filling component. ${ }^{[28]}$

\section{Other biomedically relevant materials}

There are several other promising biocompatible polymer matrices capable of performing vital functions for successful applications in tissue and biomedical engineering. One example is polyurethane (PU), composed of an organic chain unit tied by urethane linkages. Although many of them are inherently thermosets, PUs have now been reformulated for biomedical advancements to afford high mechanical integrity, high flexibility, processability, and most importantly, good biocompatibility. Today's PUs support a wide range of biomedical applications including dialysis, artificial hearts, balloon pumps, wound dressings, etc. ${ }^{[28]}$ Thermoplastic PUs (TPU), with humanprotein-like molecular structures, are potential candidates for a number of important biomedical applications (e.g., dialysis and cardiovascular devices) that require adhesion strength and biomimetic properties. ${ }^{[28]}$

Polymethyl methacrylate (PMMA), a transparent, lightweight thermoplastic resin, and synthesized by polymerizing methyl methacrylate, is also beneficial in several biomedical applications including intraocular eye lenses, bone cements for affixing implants, dentures, dental filling materials, ocular prostheses, and cosmetic surgery, all of which are because of the polymer's good biocompatibility with human tissue. ${ }^{[28]}$ PMMA is also used in the fabrication of microfluidic biochip devices and bioprocess chromatography columns for the advancement in the fields of biotechnology and biomedical engineering. ${ }^{[28]}$

Polymer bioconjugates are hybrid macromolecules prepared from natural (e.g., proteins, nucleic acid, carbohydrates, and lipids) and synthetic polymers, and have also been developed due to their improved stability, versatile bioactivity, and promising therapeutic properties. ${ }^{[75]}$ PEG, PLA, and PCL are the most commonly used synthetic polymers for bioconjugation, in which antimicrobial, disease treatment, drug delivery, and various other biomedical applications can be realized. ${ }^{[76]}$ Detailed discussion and information on polymer bioconjugates can be found in a number of review articles. ${ }^{[75,76]}$

\section{D printing for biomedical applications}

\section{Photopolymerization \\ Stereolithography}

Among the 3D-printing techniques available, stereolithography (SLA) is considered one of the most versatile and effective in terms of build times, spatial resolution, surface finishing, and chemistries available..$^{[5,77,78]}$ It is based on photopolymerization wherein a liquid photosensitive thermoset resin is exposed locally to UV laser and is then cured and solidified in layers. ${ }^{\text {[79] }}$ Commercial SLA resins contain reactive, UV-curable monomers/oligomers or their blends capable of crosslinking, and photoinitiators (PI) to activate polymerization. ${ }^{[77,78]}$ Likewise, in SLA, the initial printed parts are built in a "green state"they are not completely cured during printing. Thus, a postcure treatment by UV and/or thermal exposure is necessary to guarantee further curing of the polymer and improvement in its dimensional accuracy and mechanical properties. ${ }^{[79-81]}$ Acrylic-based resins are widely used due to their excellent biocompatibility, high heat resistance, and rapid reactivity. ${ }^{[78,82]}$ Thus, they are often utilized as suitable materials for highresolution prototyping of complex biomedical devices such as dental implants and tissue engineering scaffolds. ${ }^{[83,84]}$ A study of Arcaute et al. ${ }^{[85]}$ utilized PEGDMA as 3D bioactive constructs to encapsulate human dermal fibroblasts. Miao et al. ${ }^{[86]}$ developed biocompatible 3D scaffolds from epoxidized soybean oil acrylate capable of supporting growth of multipotent human bone marrow mesenchymal stem cells (hMSCs). Castro et al. ${ }^{[87]}$ used PEGDA as a bulk printing matrix material for osteoconductive nanocrystalline hydroxyapatite (nHA) (primary inorganic component of bone) and core-shell poly(lacticco-glycolic) acid (PLGA) nanospheres encapsulated with chondrogenic transforming growth factor $\beta 1$ (TGF- $\beta 1$ ) for sustained delivery [Fig. 2(a)].

A class of polymeric materials based on monomers of thiol and alkene groups is also useful for SLA fabrication of biomedical devices ${ }^{[88,89]}$ One major advantage of these materials is their PI-free polymerization because thiol groups are activated directly by UV light. PIs often cause problems concerning the biocompatibility of polymers and are responsible for fast aging. A study by Hoffman et al. ${ }^{[88]}$ [Fig. 2(b)] utilized new resin formulation of poly(ethylene glycol) divinyl ether and pentaerythritol tetrakis(3-mercaptopropionate) for fabrication of scaffold-like structure and showed that off-stoichiometric amounts of functional groups in the monomers allow to produce scaffolds with functional surfaces. Barker et al. ${ }^{[89]}$ used thiol-ene chemistry to crosslink a side-chain-functionalized poly(carbonate) in a microstereolithographic process. In this study, good biocompatibility was demonstrated even though a PI (Irgacure 784) was used to crosslink the material with light at $\lambda=465 \mathrm{~nm}$.

\section{Digital light processing}

Digital light processing [DLP, Fig. 3(a)] is another class of vat photopolymerization (VP) 3D printing, which takes the advantage of a digital micromirror device to project a mask of light that simultaneously cures a layer in seconds (mask projection-based process). Compared to SLA, DLP prints in a higher speed but also possesses intrinsic lesser accuracy. Unlike DLP, after SLA, a post-treatment is usually required because the laser scanning pattern focuses mostly along the outline of each layer to reduce the building time. This approach leaves 

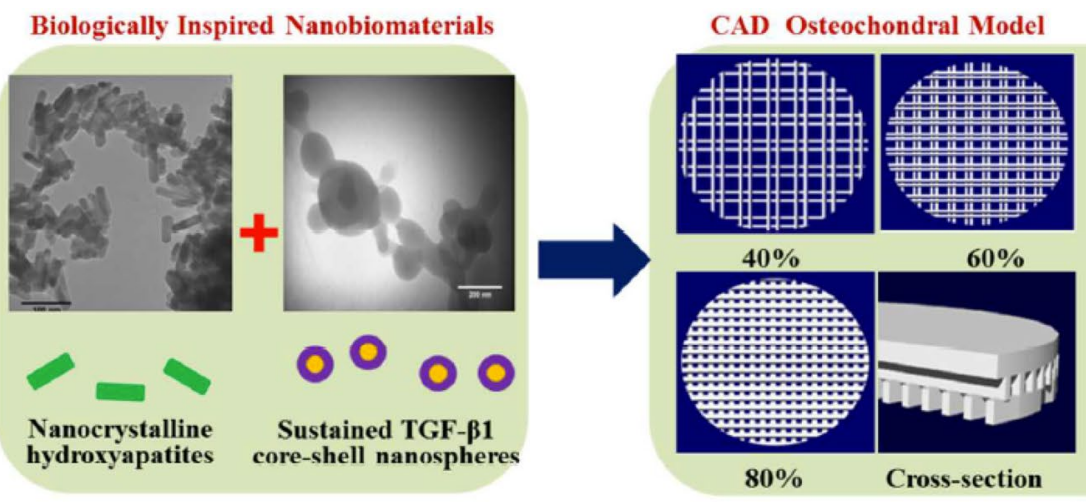

3D Scaffold Bioprinting

(a)
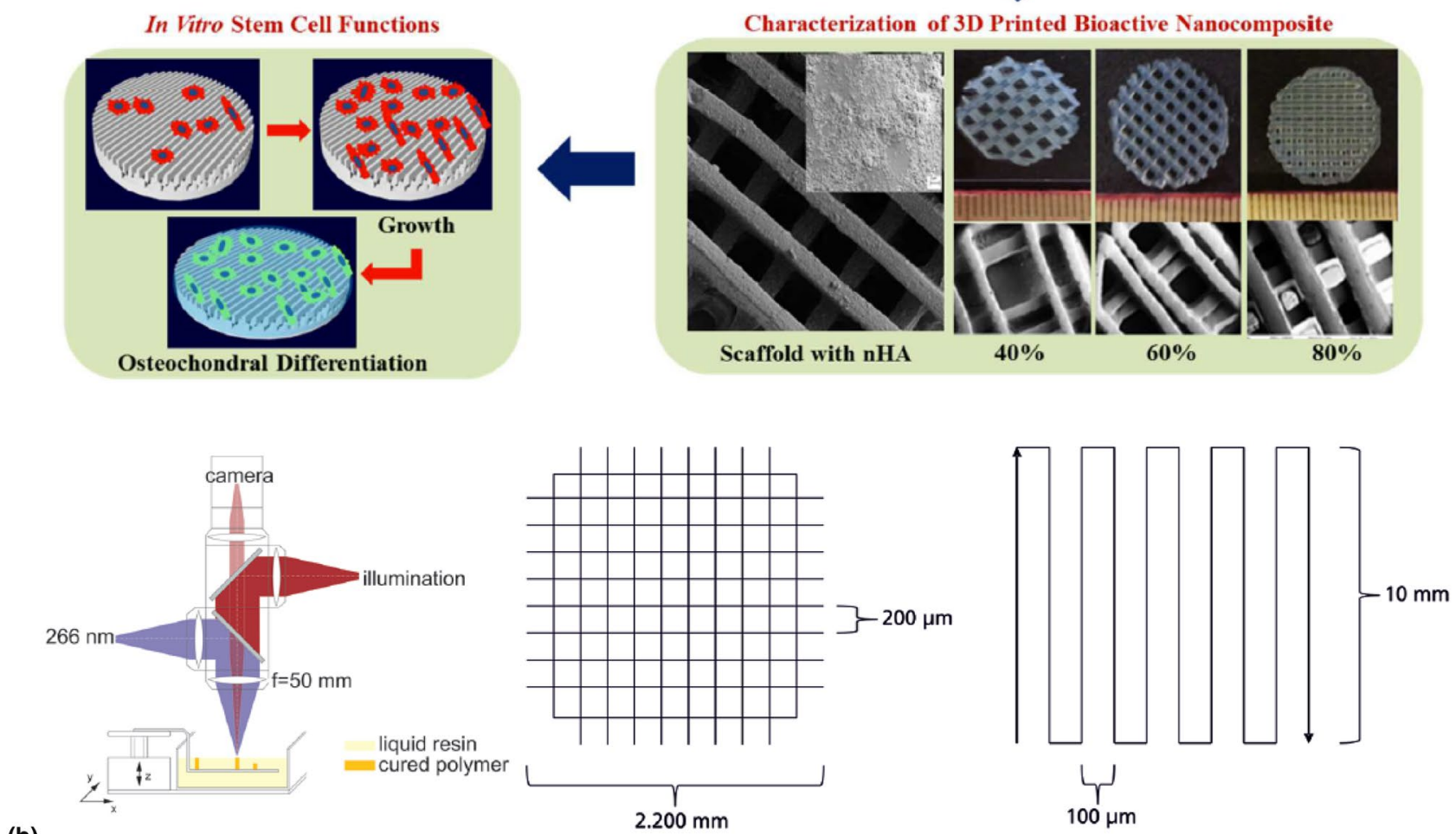

(b)

Figure 2. (a) Flowchart showing the SL printing of PEGDA biomimetic nanocomposite osteochondral scaffold composed of $\mathrm{nHA}$ and TGF- $\beta 1$-loaded PLGA nanospheres for hMSC differentiation. Also shown are CAD model of porous scaffold design and composition, and 3D-printed bioactive scaffolds via table-top SL and in vitro hMSC studies. Reprinted from Ref. 83 with permission from RSC. (b) Scheme of SLA. (b) Illumination pattern for scaffold production, and (c) Illumination pattern for the meander-shaped 2.5D specimen. Reprinted from Ref. 84 with permission from RSC.

some resins uncured inside the object, which must be postcured either by UV or thermal curing. The intrinsic advantage of DLP is its capability to cure the whole surface of the layer at once, with no difference between the outline and the inner area, making post-curing less necessary. ${ }^{[78]}$

Different biomaterials ranging from biopolymers and bioceramics to various biocomposites have been processed by DLP for possible medical applications. The chemistry is similar to that of SLA in that it makes use of acrylate or vinyl polymerization chemistry and a host of monomer, crosslinker, initiator, chain transfer agent, photosensitizer, and specialty additives in the mixture.

\section{Extrusion}

Extrusion-based technology is another promising technology in the field of 3D printing, now widely used to make scaffolds for tissue engineering. There are two main types 

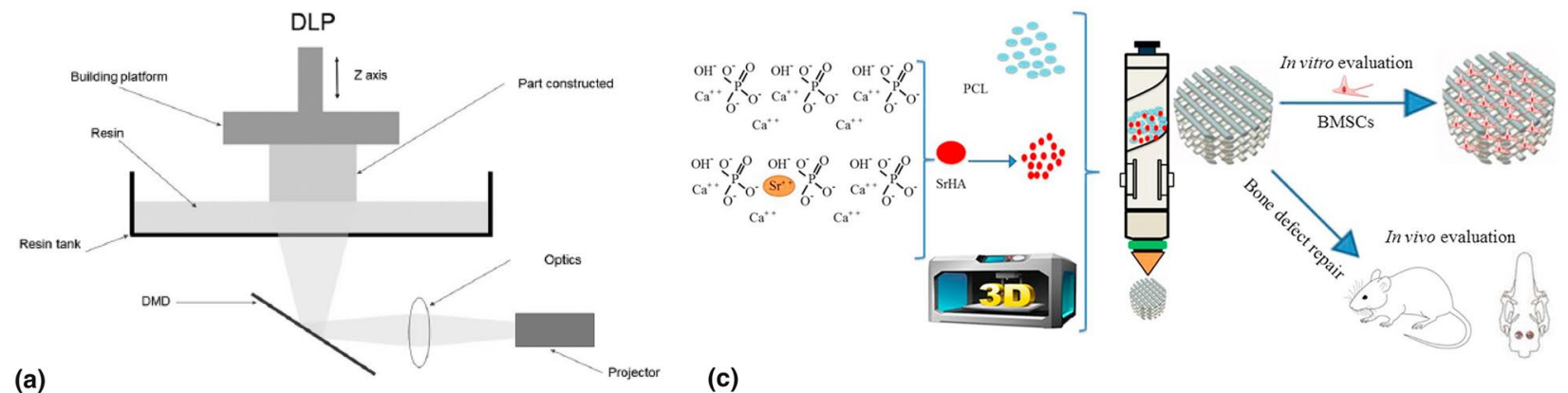

(a)

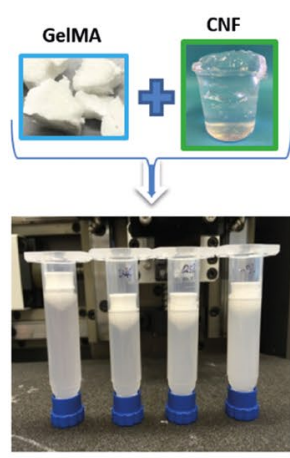

(b)

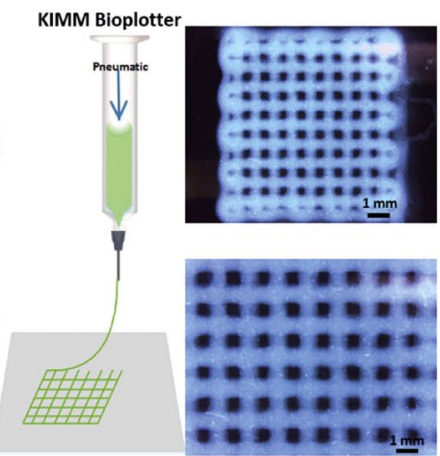

DIW printing $\Longrightarrow$ Scaffolds

(c)

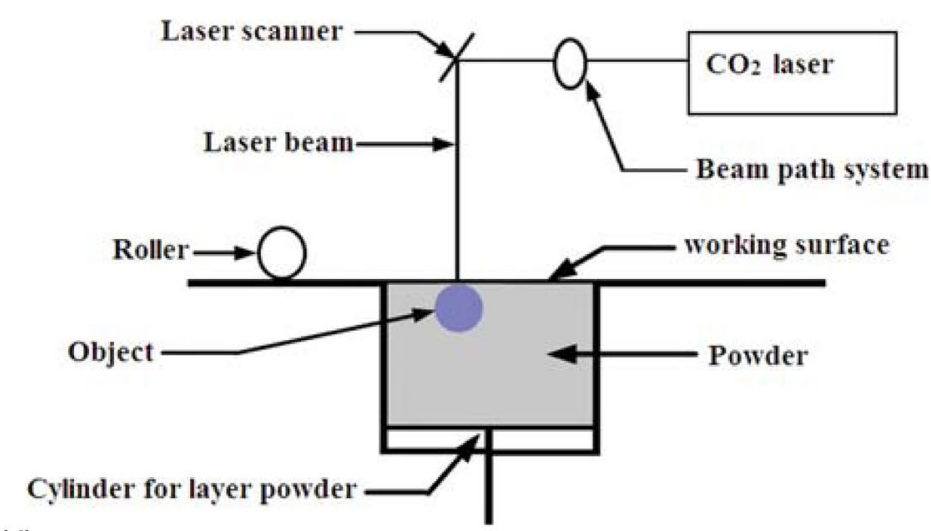

(d)

Figure 3. (a) Schematic representation of a DLP system. Reprinted from Ref. 74 with permission from Sage. (b) Preparation of PCL/ SrHA scaffold for bone tissue engineering. Reprinted from Ref. 87 with permission from Elsevier. (c) GelMA and CNF hydrogel and their formulation process, with an illustration of direct ink writing (DIW) printing working principle and optical microscopic images of the printed hydrogel scaffolds. Reprinted from Ref. 92 with permission from ACS. (d) Schematic illustration of the SLS process. Reprinted from Ref. 96 with permission from Wiley.

of extrusion-based technology: fused deposition modeling (FDM) technology and 3D plotting technology.

\section{Fused deposition modeling}

FDM technology is based on the use of polymer filaments. The filament is fed to a printing head and extruded from the nozzle when the temperature achieves the appropriate melting point. The most popular biocompatible polymers used in FDM are PLA, PCL, PLGA, and PLC. These polymers, however, are limited by their poor cell adhesion and proliferation performance. To solve this problem, a biocompatible filler is often mixed with these polymers to make composite materials with better properties.

Several studies have reported that polymer composite materials exhibit better biocompatibility than their pristine polymer equivalents when used with FDM technology. Alemán-Domínguez et al. ${ }^{[90]}$ reported the reinforcement of PCL scaffold with microcrystalline cellulose (MCC). The result of vitro cell seeding showed that the MCC had reinforcement effects on the proliferation of bone marrow mesenchymal stem cells (BMSCs) from sheep. Liu et al. ${ }^{[91]}$ reported a PCL/strontium-containing hydroxyapatite (SrHA) scaffold using FDM technology [Fig. 3(b)]. The proliferation and osteogenic differentiation properties of BMSCs cells were evaluated via in vitro cell culture test. Results revealed that the SrHA facilitated the cell proliferation and differentiation. In vivo bone regeneration test also showed that the bone regenerated more quickly in the absence of SrHA. Li et al. ${ }^{[92]}$ demonstrated the biocompatibility of the PCL scaffold with the self-assembling peptide hydrogel (SAPH) coating. The vitro cell culture test revealed that more rabbit BMSCs were attached to the scaffold compared to pure PCL scaffold. Additionally, the vivo test showed that the SAPH coating promotes the regeneration of the osteochondral. Rasoulianboroujeni et al. ${ }^{[93]}$ reported the utility of PLGA/ $\mathrm{TiO}_{2}$ in bone tissue engineering. $\mathrm{TiO}_{2}$ improves the wettability of the PLGA scaffold and favors cellular attachment. The result of the cell culture test indicated that the osteoblast proliferation activity of $\mathrm{PLGA} / \mathrm{TiO}_{2}$ scaffold was better than that of the pure PLGA scaffold. Lai et al. ${ }^{[94]}$ incorporated a biodegradable $\mathrm{Mg}$ metal into PLGA/TCP porous scaffold by 3D printing. Results showed that the scaffold exhibited better biological performance compared to the pure PLGA scaffold in terms of biosafety to the vessel and body of a rabbit.

\section{$3 D$ plotting}

3D plotting, also known as 3D dispensing, direct-write bioprinting, and 3D microextrusion, is a technology that uses 
bioink to be extruded with high pressure air. Commonly used bioinks include gelatin, alginate, collagen, and other hydrogels. The development in biocompatible ink for 3D plotting technology follows the same trend as the biocompatible polymer in FDM technology. Several research studies have focused on the use of composite bioink due to its better biocompatibility.

Liu et al. ${ }^{[95]}$ fabricated a scaffold composed of methacrylated gelatin (GeIMA) hydrogel and nanohydroxyapatite (nHA) for osteochondral defect repair. The biocompatibility was analyzed using vitro test for BMSCs. Results showed that the regeneration of tissue had good integrity and smooth surface. Xu et al. ${ }^{[96]} 3 \mathrm{D}$-printed a porous scaffold using GelMA/cellulose nanofibrils (CNFs) ink [Fig. 3(c)]. The printed scaffold exhibited non-cytotoxicity to the fibroblasts, which showed high bioactivity in the cell culture test. Lin et al. ${ }^{[97]}$ also fabricated a printed scaffold based on alginate (Alg) and $\varepsilon$-polylysine (PL). Results revealed that the surface charges of the scaffold regenerated and the presence of $\varepsilon$-PL improved the stability of the scaffold. The scaffold also favored the adhesion and spreading of the cells in the human BMSCs cell culture test. Luo et al. ${ }^{[98]}$ 3D-printed a bioactive glass (BG)/Alg scaffold for bone regeneration. Results indicated the presence of bioactive ions around the scaffold in the absence of BG, while the BG/Alg scaffold itself provided an ideal environment for cell adhesion, spreading, and proliferation. Wu et al. ${ }^{[1]}$ demonstrated the biocompatibility of a collagen/gelatin/alginate scaffold fabricated using bioprinting technology, in which human corneal epithelial cells (HCECs) were added to the ink. Results showed that the scaffold modified the extracellular matrices (ECM) of the HCECs and the cells showed better cell viability performance.

\section{Sintering}

Selective laser sintering [SLS, Fig. 3(d)] is a rapid prototyping (RP) technology that uses infrared laser beam to create layerby-layer solid objects from heating and fusion of powdered materials. ${ }^{[99]}$ During printing, the unfused powder supports the part and eliminates the need for dedicated supports. ${ }^{[100]}$ This feature makes SLS 3D-printing technology produce objects free of residual stress and internal defects that can plague commonly manufactured components and other 3D-printing techniques. ${ }^{[101]}$ These advantages make SLS an ideal RP technology for fabricating structures with complex geometries, including interior features, undercuts, thin walls, and negative features. ${ }^{[102]}$ SLS process technology has been proven to have no adverse effects on the biocompatibility of powder materials. In vitro tests were carried out in a study ${ }^{[103]}$ to assess cellular responses, in terms of cell attachment, morphology, proliferation, differentiation, and mineralized nodule formation, using primary human osteoblast cells. Results showed that the processed SLS composite was biocompatible, with no adverse effects observed on the cell viability and metabolic activity, thereby, supporting a normal metabolism and growth pattern to osteoblast cells.

One application of SLS 3D-printing technology in the field of medicine is a combined image-based computational design techniques and solid free-form fabrication (SFF) method. SLS is beneficial in fabricating bone tissue engineering constructs for sites including the temporo-mandibular joint (TMJ) due to its cost-effectiveness and efficiency. ${ }^{[104]}$ Compared to other 3D-printing technology, SLS can fabricate scaffolds by using any powdered fusible biomaterial without decomposition under a laser beam. ${ }^{[105,106]}$ Biomaterials such as polyetheretherketone (PEEK) and hydroxyapatite (HA) are a few examples, which commercial SLS RP system is able to process. The SLS technique is advantageous as it offers tunable process parameters and good user control over the scaffold microstructures. Tan et al. ${ }^{[105]}$ determined the biocompatibility of the SLS-fabricated PEEK/HA scaffolds through micro-structural assessments using electron microscopy. Results showed that the material did not degrade, while retaining its biocompatibility. Thus, SLS makes it easy to incorporate multiple materials because of its welladapted technology, especially for the fabrication of tissue engineering scaffolds.

SLS technology is also capable of fabricating a porous PCL scaffold with low stiffness for cardiac tissue engineering using a computer-aided system for tissue scaffolds (CASTS) system, a predetermined design automation method. The CASTS system enables the design of customizable scaffolds without depending on the design skill of the user. While providing consistency and reproducibility in building complicated scaffolds, SLS can produce scaffolds with micropores suitable for cell attachments. The macroarchitecture of the scaffold can be modified to create scaffolds of different macropore sizes by changing the elemental cell design in CASTS. Yeong et al. ${ }^{[107]}$ determined the biocompatibility of 3D-printed scaffolds by monitoring the formation of multinucleated myotubes in the scaffold via vitro cell culture using $\mathrm{C} 2 \mathrm{C} 12$ cells cultured for 11 days. The $40-80 \%$ porosity of the micropores produced was required for the cardiac myocytes to be seeded at high and spatially constant density, while the cell viability and functions through the scaffolds were maintained. A stable cell colony was detected for 21 days, making the scaffold promising for cardiac and skeletal muscle tissue engineering.

Overall, SLS technology is suitable for fabricating porous and full-density 3D-printed parts from biocompatible materials. These fabricated parts can be utilized in non-stressed areas of the human body as engineered tissue structures, cellular matrices, and drug delivery systems. ${ }^{[108]}$ SLS technology can also provide excellent control over the geometry of scaffolds and guarantees complete interconnected pores, making them useful in tissue engineering applications such as fractured bone replacement and new bone regeneration. ${ }^{[102]}$

\section{Effects of processing conditions}

The biocompatible materials are subject to several processing conditions, either during or after printing. These conditions include light, heat, and chemical exposures, all of which can possibly influence the biocompatibility of the resulting 3D-printed products. 


\section{Curing}

Polymers undergoing curing process are prone to risk of losing their biocompatibility. Excessive heating and stirring, misuse of organic solvents, and improper UV exposure can often result in low-quality 3D-printed products. Both thermal and UV curing may call for the need for initiators and photosensitizers. Although initiators and other additives may help facilitate the printing process and/or improve the mechanical properties of the printed product, they still represent materials foreign to the base polymer constituents.

\section{Photo-curing}

Photo-curing is a general term related to two different concepts, photoinduced polymerization and photo-crosslinking reaction. A typical UV-induced free radical polymerization is characterized by a series of steps, including light absorption by the PI, radical $\left(\mathrm{R}^{\circ}\right)$ generation, reaction initiation, propagation, and termination [Fig. 4(a)]. Monomer M undergoes initiation producing $\mathrm{RM}^{*}$, which subsequently converts to larger molecular weight species $\mathrm{RM}_{n+1}$ until the reaction is terminated. On the other hand, a photo-crosslinking reaction uses a crosslinker (in general, bifunctional molecules, e.g., diacrylates) and an oligomer with a crosslinkable site (e.g., polyesters, polyethers, polyurethanes, etc.) [Fig. 4(b, c)].$^{[109-112]}$ Photo-curable 3D-printing inks use both mechanisms in order to tailor the physicochemical properties of the resulting printed parts for different applications.

Gelatin and collagen are both prime examples of biomaterials that are usually cured or post-treated to enhance their performance. These biomaterials are suitable for soft tissue engineering and have been used in the field. ${ }^{[113,114]}$

Aiming to build on the success of photosensitive gelatin methacrylamides for tissue 3D printing, ${ }^{[115]}$ post-processing UV curing on cell-laden gelatins was performed involving free radical crosslinking. ${ }^{[116]}$ Aside from the positive effects of UV post-curing on the structural integrity and mechanical properties of the resulting scaffolds, the effects on using different PIs, such as Irgacure 2959, which resulted in less cytotoxic environments, ${ }^{[117]}$ should also be studied. PIs also have considerable effects on the overall biocompatibility of a printed product, whether used during the printing or post-cure process.

\section{Photoinitiators (PIs)}

A photoinitiator (PI) is a compound, which produces reactive species needed for initiating crosslinking or polymerization reactions. In order to increase the chemical conversion, a PI should exhibit high absorbance within the emission range of the UV light source, which varies with irradiance, radiant power, and wavelength range. The initiation rate and penetration of the incident light both depend on the type, efficiency, and absorption wavelength of the PI. Furthermore, the PI should have a high extinction coefficient, that is, its excited states should exhibit a short lifetime to prevent quenching by oxygen or oligomers. $^{[110,118]}$

Based on the mechanism by which initiating radicals are formed, PIs are generally classified as unimolecular or bimolecular. ${ }^{[119]}$ The former undergoes a unimolecular bond cleavage upon irradiation to yield free radicals, while the latter a bimolecular reaction, where the excited state of the PI interacts with a second molecule (a coinitiator) to generate free radicals. ${ }^{[110,118]}$ Benzoin ethers were the first unimolecular PIs used in large scale, as these compounds undergo cleavage to form benzoyl and benzyl ether radicals [Fig. 4(d)]. Photoexcited benzophenone and related diarylketones do not cleave to give free radicals, but can abstract hydrogens from a hydrogen donor to yield free radicals that initiate polymerization [Fig. 4(e)]. ${ }^{[18]}$ The choice of an appropriate PI depends on different factors including the substrate used, UV lamp specifications, curing conditions, chemistry of the formulation, curing speed, and final application.

Hydrophilic 2-hydroxyethyl methacrylate (HEMA) is a commonly used UV-polymerizable monomer. The effect of the chemical structure and concentration of different PIs on the rate of polymerization and some physicochemical properties of HEMA-derived hydrogels were investigated (Fig. 5). ${ }^{[120]}$ In general, the unimolecular PIs were more active compared to the bimolecular ones. Among the unimolecular initiators, 2,2-dimethoxy-2-phenyl acetophenone displayed the highest efficiency, followed by benzoin methyl ether, perhaps due to the extra methoxy group, which resulted in a more active phenyldimethoxy methyl radical and subsequent cleavage to methyl radical.

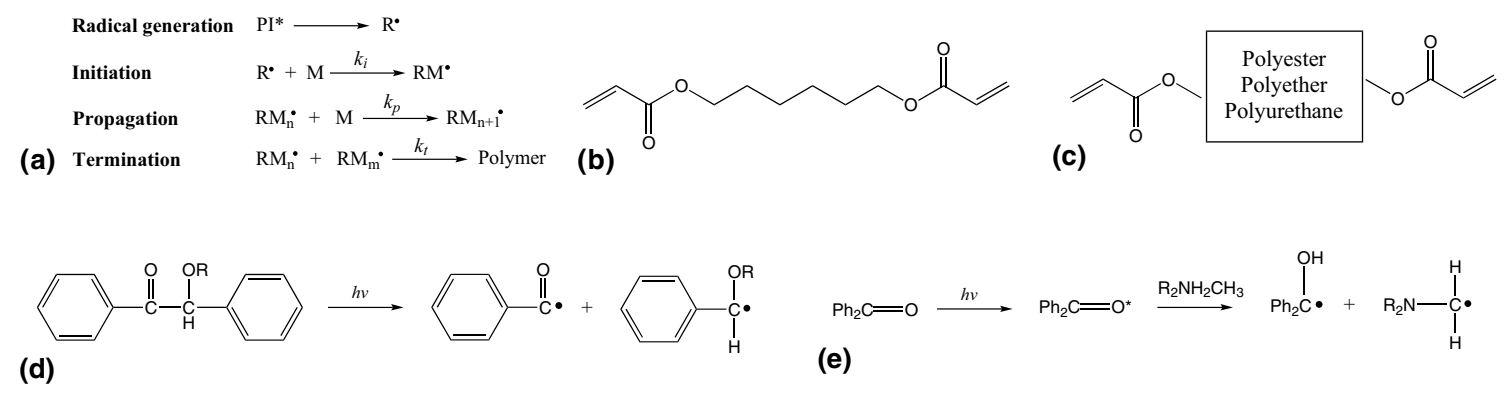

Figure 4. (a) Free radical polymerization initiated by UV light. Example of (b) crosslinker, (c) oligomers, (d) Unimolecular, and (e) bimolecular Pls. 
Figure 5. Library of photoinitiators (PIs) with the associated maximum UV absorbance $\left(\lambda_{\max }\right)$ and molar extinction coefficient $(\varepsilon)$. $U$ unimolecular and $B$ bimolecular.

\begin{tabular}{|c|c|c|c|c|c|}
\hline Type & Photoinitiator & Chemical structure & $\begin{array}{l}\lambda_{\max } \\
(\mathrm{nm})\end{array}$ & $\begin{array}{c}\varepsilon \\
\left(\mathrm{L} \mathrm{mol}^{-1} \mathrm{~cm}^{-1}\right)\end{array}$ & Reference \\
\hline $\mathrm{U}$ & $\begin{array}{l}\text { Benzoin methyl ether } \\
\text { (BME) }\end{array}$ & & 323 & - & [116] \\
\hline U & $\begin{array}{l}\text { 2,2-Dimethoxy-2- } \\
\text { phenyl acetophenone } \\
\text { (Irgacure-651) }\end{array}$ & & 335 & 94.6 & [116-118] \\
\hline$U$ & $\begin{array}{l}\text { 2-Hydroxy-2,2- } \\
\text { dimethyl } \\
\text { acetophenone } \\
\text { (Darocur-1173) }\end{array}$ & & 320 & - & [116] \\
\hline$U$ & $\begin{array}{l}\text { 1-Hydroxycyclohexane } \\
\text { acetophenone } \\
\text { (Irgacure-184) }\end{array}$ & & 326 & - & [116-118] \\
\hline$U$ & Benzophenone & & 255 & & [115] \\
\hline U & $\begin{array}{l}\text { 2,2-Diethoxy } \\
\text { acetophenone } \\
\text { (DEAP) }\end{array}$ & & 323 & 7.7 & [116] \\
\hline$U$ & $\begin{array}{l}\text { 4-(2-Hydroxyehtoxy) } \\
\text { pheny1-2-hydroxy-2- } \\
\text { propyl ketone } \\
\text { (Darocur-2959) }\end{array}$ & & $<313$ & - & [116] \\
\hline U & $\begin{array}{l}2,4,6- \\
\text { Trimethylbenzoyl } \\
\text { diphenylphosphine } \\
\text { oxide }\end{array}$ & & $<400$ & - & {$[108]$} \\
\hline U & $\begin{array}{l}\text { 2-Hydroxy-4'-(2- } \\
\text { hydroxyethoxy)- 2- } \\
\text { methylpropiophenone } \\
\text { (Irgacure-2959) }\end{array}$ & & 365 & 6.7 & {$[117,118]$} \\
\hline U & $\begin{array}{l}\text { 2-Methyl-4'- } \\
\text { (methylthio)-2- } \\
\text { morpholinopropiophen } \\
\text { one (Irgacure-907) }\end{array}$ & & 365 & 120.8 & [117] \\
\hline B & $\begin{array}{l}\text { Thioxanthne-9-one } \\
\text { (TXN) }\end{array}$ & & 378 & - & [116] \\
\hline B & $\begin{array}{l}\text { N-Methyl } \\
\text { diethanolamine } \\
\text { (MDEA) }\end{array}$ & & - & - & {$[116]$} \\
\hline
\end{tabular}

Bryant and coworkers ${ }^{[121]}$ investigated the effects of different PIs (Irgacure 184, 651, 907, and 2959), their concentration (from 0.01 to $0.1 \mathrm{wt} \%$ ), as well as the presence of UV light on the cytocompatibility of cultured NIH/3T3 fibroblasts in vitro. At low PI concentration, all molecules were cytocompatible, except Irgacure-651, which exhibited a relative survival of $\sim 50 \%$ lower than the control group. In the presence of initiating light ( $\sim 6 \mathrm{~mW} \mathrm{~cm}{ }^{-2}$ of $365 \mathrm{~nm} \mathrm{UV} \mathrm{light),} \mathrm{Irgacure}$ 2959 displayed the best performance. To evaluate the potential of cytocompatible photoinitiating systems, chondrocytes were encapsulated in a photo-crosslinked hydrogel using $0.05 \mathrm{wt} \%$
Irgacure 2959. Upon photopolymerization for $10 \mathrm{~min}$, nearly all chondrocytes have survived the process.

In order to explore the development of biocompatible photopolymerizing polymers for biomedical engineering applications, the cellular toxicity of three PIs (Irgacure 184, 651, and 2959) on six different cell populations commonly used for engineering tissues was investigated. ${ }^{[122]}$ Irgacure 2959 had the least cell deaths over a wide range of mammalian species. Also, a correlation between cellular proliferation rate (i.e., population doubling time) and increased PI cytotoxicity was observed. 
Different tetrazoles with photoactivation wavelengths between 302-405 nm were obtained by tetrazole-alkene cycloaddition (or photo-click chemistry), and their use for protein labeling was explored. ${ }^{[123]}$ Hydrogels of a 4-arm PEGmethacrylate (PEG-4) and tetrazole derivative were synthesized using the same method and were found to be soluble at physiological conditions (i.e., $\mathrm{pH} 7.4$ at $37^{\circ} \mathrm{C}$ ) for up to a concentration of $60 \mathrm{wt} \%$. Furthermore, cell experiments demonstrated that the hydrogels were non-cytotoxic, and in vitro release studies showed that cytochrome $c, \gamma$-globulins, and recombinant human interleukin-2 were all released from PEG-4-tetrazole hydrogels in a sustained and quantitative manner over a period of 14 to $20 \mathrm{~d} .^{[124]}$

\section{Effect of UV light}

Typically, when photocured formulations are exposed to $\mathrm{UV}-\mathrm{Vis}$ light and other conditions such as presence of oxygen, humidity, and toxic agents in the atmosphere, photooxidation of the polymer matrix occurs. This photoaging or damage of the cured material can lead to a decrease in gloss, cracking, color change (i.e., yellowing or whitening), blistering, and loss of adhesion. ${ }^{[109,125]}$

Polyethylene terephthalate (PET), one of the most widely used and commercially important engineering polymeric materials, was recently shown to be suitable for fused filament fabrication and use in AM. ${ }^{[126]}$ Gordon and coworkers ${ }^{[127]}$ exposed three commercially available PET grades (neat, PET containing a UV stabilizer, and PET containing $\mathrm{TiO}_{2}$ ) to different accelerated weathering conditions, coupled with varying exposure times to UV light, different temperatures and relative humidity. Results showed that the formation of hydroxy-substituted terephthalate units only occurred under exposure to UV radiation and their relative concentration increased in the presence of moisture. The PET with UV absorber was initially effective in limiting the formation of monohydroxy-terephthalate, except during prolonged exposure times. The presence of $\mathrm{TiO}_{2}$ was also found to decrease the rate of formation of hydroxy-substituted terephthalate units.
Poly(vinyl chloride) (PVC) is an extensively used thermoplastic material due to its superior mechanical and physical properties, and high chemical and abrasion resistance. However, PVC is prone to photochemical degradation when exposed to UV irradiation. To slow down its oxidation under UV, researchers have functionalized PVC by covalently bonding benzophenone-derivative groups to its backbone via copper-catalyzed Huisgen-Click cycloaddition reaction. Results showed that the modified PVC was non-toxic versus HaCaT cells and displayed outstanding resistance to photoaging for more than $200 \mathrm{~h}$ of UV irradiation. ${ }^{[128]}$ Although photoaging processes generally have a negative impact on material properties, the development of photoinduced properties can actually further enhance the performance of materials in different applications. A number of polymers were reported to have photoinduced optical, electric, and mechanical properties. ${ }^{[129,130]}$

Marozas et al. ${ }^{[131]}$ synthesized a PEG-based hydrogel, designed with an allyl sulfide crosslinker and a covalently tethered PI. The allyl sulfide moiety is known to participate in a radical-mediated addition fragmentation chain transfer (AFCT) reaction, which provides viscoelasticity to the hydrogel. Figure 6(a) shows the rheological profile of loss modulus $\left(G^{\prime \prime}\right)$ during and after UV irradiation for $10 \mathrm{~s}$. A $240 \%$ increase in $G^{\prime \prime}$ from 20 to $48 \mathrm{~Pa}$ over a 10 -s irradiation was observed. Although this result corresponded to a viscoelasticity increase, a decrease in $G^{\prime \prime}$ to $20 \mathrm{~Pa}$ within an 8-s light shuttering off was observed. Photoinduced viscoelasticity in these gels was also found to be reproducible over 8 successive rounds of $10 \mathrm{~s}$ irradiation, as shown in Fig. 6(b). Moreover, human mesenchymal stem cells (hMSCs) cultured on the hydrogel substrates spread and were viable throughout the photochemically induced viscoelasticity changes.

\section{Effect of heat}

Subjecting materials to high temperatures has always been a good alternative to using chemical agents for sterilization. As such, it only stands to reason that the effects of heat on the biocompatibility of 3D-printed materials be investigated.
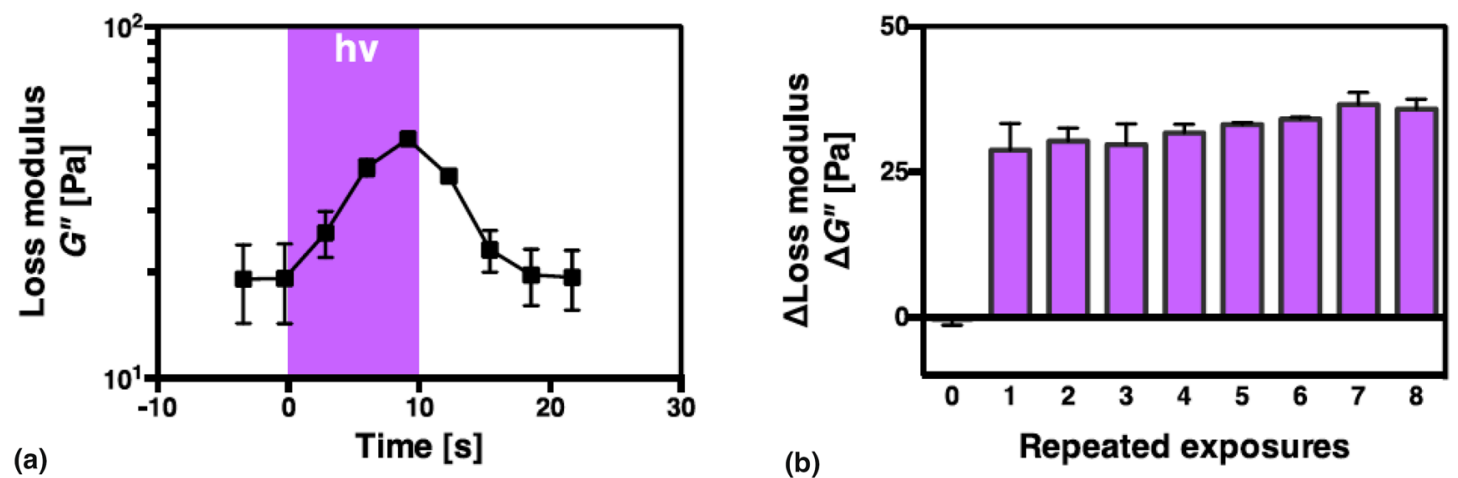

Figure 6. (a) Loss modulus of PEG-based hydrogel during and after irradiation for $10 \mathrm{~s}\left(2.5 \mathrm{~mW} \mathrm{~cm}^{-2}, 365 \mathrm{~nm}\right.$, purple region). (b) The maximal changes in G" for consecutive exposures in the same conditions. Reprinted from Ref. 127 with permission from IOP. 
In the case of using PMMA in the manufacture of implants (via FDM 3D printing) that have direct surface interaction with bones, biocompatibility is more focused on the lack of negative immune responses from the body and the prevention of osteomyelitis, a bone infection brought on by either bacteria or rarely, fungi. PMMA is usually doped with broad-spectrum antibiotics for implantation on the site of infection, which will then be retrieved at a later time. ${ }^{[132]}$ In one research, PMMA was extruded through a print head heated at $175^{\circ} \mathrm{C}$ for layer printing. The aim was to produce a 3D-printed PMMA implant having resorbability into the human body, good antibacterial properties, and ability to be produced through FDM. ${ }^{[133]}$ Cytotoxicity was not a major concern in this study, only the effect of heat on the antibacterial or bacteriostatic properties of PMMA was investigated.

Another example is polysiloxane/bioactive glass (BG) film used for coating biomedical devices. The effect of curing in oxidative atmosphere at 260 and $500^{\circ} \mathrm{C}$ on the cytocompatibility of the end product was investigated. The researchers made use of MG-63 osteoblast-like cells to prove that heatcuring does not elicit cytotoxic effects in the resulting product. After $48 \mathrm{~h}$ of incubation, surfaces, crosslinked at $260^{\circ} \mathrm{C}$, formed thinner cell layers as opposed to surfaces crosslinked at $500^{\circ} \mathrm{C}$. The overall appearance of the expressed morphology of the MG-63 indicates a high cell viability on the BG/ MK(H62C) sample. ${ }^{[134]}$

Organic powders are natural polymers that are also used in bioprinting. Organic powders as opposed to bioinks, which are highly viscous in nature, are often used for 3D-printing scaffolds requiring denser and higher mechanical integrity for higher load bearing applications. However, many organic powders do not respond to light and degrade when heated, reducing their suitability for 3D-printing methods using light or heat. Biomolecules, when exposed to high levels of light and heat, also damage the biomaterial and degrade it. These phenomena make SLA, SLS, and SLM printing methods highly inadequate for making use of light- and heat-sensitive biomaterials. ${ }^{[135]}$

On the other hand, inkjet bioprinting, which delivers small droplets of bioink during printing, uses thermal pulses through a heating element that can reach up to $300^{\circ} \mathrm{C}$, without affecting the cells. The very short exposure of the bioink to heat is not enough to cause any further damages, having no detrimental effects on cell viability. ${ }^{[136,137]}$

\section{Biocompatibility testing}

Biocompatibility evaluation is a crucial step in proving the safety of any biomedical product. Something as simple as material purity can have significant ramifications, if not verified. These impurities may occur as a by-product of a process or trace quantities in the product itself. ${ }^{[138]}$ All biological effects should be identified, investigated, and documented. Impurities are classified as either extractable or leachable, but both are undesired in any biomedical product. Extractables are byproducts that are expected to form under controlled experimental environments, while leachables are released from the final product formed, so extractables may no longer exist in the product. ${ }^{[139]}$

Natural polymers present considerable challenges in the form of contaminants that are easily included in their manufacture. Microbiological agents including microorganisms and microbes can easily be found in the natural state of these polymers and cellulosic materials can bring this contamination forward into the printing process. These contaminants can cause inflammation and sepsis, both leading to tissue damage. ${ }^{[140]}$

\section{Endotoxin detection}

One way to determine a material's biocompatibility is through the detection of endotoxins. Endotoxins are lipopolysaccharides (LPS) found in the cell membrane of bacteria. A single bacterium contains millions of molecules, which can be released into the environment upon death or even during reproduction. The release of endotoxins triggers inflammation, leading to tissue injury. There are two procedures approved by the FDA for endotoxin detection. One is the pyrogen test, where the material in liquid solution form is injected directly into a test rabbit's bloodstream, while observing the rabbit's immune response, especially the rise in its body temperature. This procedure is time-consuming and rarely used today. The second test, limulus ameobocyte lysate (LAL) test and other newer procedures based on it, are much more often used in the modern setting. In this test, a reaction is observed when the blue blood cells of the Limulus polyphemus, commonly known as the horseshoe crab, clot upon exposure to endotoxins. This test is much faster to perform and can be used on specimens not necessarily in liquid forms. ${ }^{[140]}$

\section{Degradation kinetics}

The in vitro degradation of biomaterials is tested by exposure to a solution that simulates the inside of the human body. In this procedure, the biomaterial in its final form is submerged in a simulated body fluid (SBF), kept consistent at body temperature $\left(37^{\circ} \mathrm{C}\right)$, under constant agitation for prolonged periods in the magnitude of multiple weeks or even months. For example, a mixture of $\mathrm{NaHCO}_{3}, \mathrm{KCl}, \mathrm{NaCl}, \mathrm{MgCl}_{2} \cdot 6 \mathrm{H}_{2} \mathrm{O}$, $\mathrm{K}_{2} \mathrm{HPO}_{4} \cdot 3 \mathrm{H}_{2} \mathrm{O}, \mathrm{Na}_{2} \mathrm{SO}_{4}$, and $\mathrm{CaCl}_{2}$ was used as SBF in specific predetermined increments in distilled water and kept at a constant $\mathrm{pH}$ of $7.4 .^{[141]}$ The material being tested is further characterized using gel permeation chromatography (GPC) at set intervals to determine loss of molecular weight over time.

\section{Bacteriostatic property testing}

In a very straightforward test, popular strains of bacteriaavailable for purchase in culture form, are introduced onto the surface of the biomaterial to study its rate of growth and survival. To simulate the performance in vitro, printed samples are placed inside well plates and subjected to measured quantities 
of bacterial suspensions. The aim is to detect the growth of biofilm via crystal violet solution staining and to perform quantification using the Gram scale. ${ }^{[141]}$

\section{Cytocompatibility testing}

If a biomaterial is claimed to be bioactive or bioinductive, testing its ability to support cell attachment and proliferation is an absolute must. ${ }^{[121,122,133,141]}$ These biomaterials are printed into scaffold constructs and cells_- hMSCs being a popular choice, are introduced to allow observation of cellular growth. Similar to bacterial testing, samples are put into wells and cell suspensions are introduced. After a period of time, cell staining kits like cell counting kit-8 (CCK-8) or the more common but less accurate haematoxylin and eosin (H\&E) staining are performed preferably by trained micropathologists to allow for cell count.

Cell attachment is tested by affixing a cell-laden scaffold with formaldehyde and decellularized through washing with surfactants like triton X-100 or sodium dodecyl sulfate (SDS) for a set period, and then washed with phosphate buffered saline (PBS) for multiple times. Subsequently, the remnant scaffold is stained with 4',6-diamidino-2-phenylindole (DAPI) to highlight the actin microfilaments, further proving that the cells in the scaffold adhered and attached correctly and underwent appropriate cell signaling processes.

Lastly, collected cells are tested in a flow cytometer to gauge cell viability. A flow cytometer can perform rapid cell counting, detect the presence of appropriate protein markers, and determine proper cell functions.

\section{Conclusions and perspectives}

Material printability, biocompatibility, desirable mechanical properties, biodegradability, safe by-products, and biomimicry are all essential requirements in the manufacture of biocompatible products. Although these factors may seem to follow a sequence-for example, a material that is deemed not printable will no longer be assessed for other requirements, and it must be stressed that all factors are equally significant. The issues with material printability can be addressed by finely tuning the 3D-printing parameters including the printing speed, infill, bed temperature (if applicable), and the like. In the case of FDM-DIW, a viscous paste ink can be achieved by inclusion of thixotropic agents (e.g., fillers and additives in micro- and nanoscale sizes). In addition, the utility of non-toxic polymeric materials for 3D printing helps reduce the generation and emission of toxic particles and volatile organic compounds (VOC). The use of biopolymer inks and filaments are eco-friendlier because they are benign, biodegradable, and generally require lower temperature during printing. Selection of an appropriate AM method is crucial in optimizing the environmental impacts and energy consumption. Moreover, the print process capability can fully be utilized by using a set of operational and optimized parameters including, but not limited to, printing speed, bed and extruder movement, post-curing temperature, and wavelength and UV exposure time, if applicable. All this makes biocompatibility investigation of 3D-printed materials require close monitoring of every step of the process. This review shows that changes to cytotoxicity and, therefore, biocompatibility of a material is significantly affected by different curing methods.

A majority of materials that undergo photopolymerization require the use of PIs and based on the limited, focused research, there is a limited quantity of PIs marketed for their cytocompatibility. Although SLA and DLP have been used extensively for scaffold printing, especially for use in bone constructs, the potential effects of the PI used in photo-curing demands further investigation. SLS has found limited use in tissue engineering. This technology may have been used in the creation of implantable devices driven by the base biocompatibility of some polymers like nylon. Research on the effect of heat on the cytotoxicity of various materials suggests that the sintering process, despite its relatively desirable resolution, is not the best available technology for use in the creation of scaffold constructs.

Taking into account the different effects of photo and thermal curing, 3D-printing methods that do not require post-curing are in a more favorable light. Extrusion methods do little to affect the printed material chemically. Although some methods like FDM use heat during the process, they are mainly used in the printing of PLA and ABS filaments, but not scaffold materials. While most of the focus on this review has been on polymer materials and matrices, consideration of hybrid polymer materials such as ceramic, metallic, and carbon-based composite and nanocomposite should be the next step. Future work should also consider the aspects of 4D printing and stimuli-responsive polymer systems as applied to the biomedical field. This can meet the possibilities of applying 3D-printed biocompatible polymer materials which can display shape memory, actuation, sensory, and even therapeutic and diagnostic (theranostic) functionality.

\section{Acknowledgments}

The authors would like to thank other members of the Advincula Research Group (Department of Macromolecular Science and Engineering, Case Western Reserve University). Technical support from Frontier Laboratories, Quantum Analytics, and Malvern Panalytical is greatly acknowledged. Scholarship support for J. Sta. Agueda from the Department of Science and Technology, DOST-PCIEERD is greatly acknowledged. Work (or Part of this work) was conducted by ORNL's Center for Nanophase Materials Sciences, which is a US Department of Energy Office of Science User Facility. 


\section{Declarations}

\section{Conflict of interest}

On behalf of all authors, the corresponding author states that there is no conflict of interest.

\section{References}

1. Z. Wu, X. Su, Y. Xu, B. Kong, W. Sun, S. Mi, Bioprinting three-dimensional cell-laden tissue constructs with controllable degradation. Sci. Rep. 6, 1 (2016)

2. M. Guvendiren, J. Molde, R.M. Soares, J. Kohn, Designing biomaterials for 3D printing. ACS Biomater. Sci. Eng. 2, 1679 (2016)

3. F. Barrere, T. Mahmood, K. De Groot, C. Van Blitterswijk, Advanced biomaterials for skeletal tissue regeneration: instructive and smart functions. Mater. Sci. Eng. R Rep. 59, 38 (2008)

4. C. Mason, P. Dunnill, A brief definition of regenerative medicine. Regen. Med. 3, 1-5 (2008)

5. C. Cha, P. Soman, W. Zhu, M. Nikkhah, G. Camci-Unal, S. Chen, A. Khademhosseini, Structural reinforcement of cell-laden hydrogels with microfabricated three dimensional scaffolds. Biomater. Sci. 2, 703 (2014)

6. A. Skardal, M. Devarasetty, H.-W. Kang, I. Mead, C. Bishop, T. Shupe, S.J. Lee, J. Jackson, J. Yoo, S. Soker, A hydrogel bioink toolkit for mimicking native tissue biochemical and mechanical properties in bioprinted tissue constructs. Acta Biomater. 25, 24 (2015)

7. F.J. 0 'brien, Biomaterials \& scaffolds for tissue engineering. Mater. Today $14,88(2011)$

8. G. Turnbull, J. Clarke, F. Picard, P. Riches, L. Jia, F. Han, B. Li, W. Shu, 3D bioactive composite scaffolds for bone tissue engineering. Bioact. Mater. 3, 278 (2018)

9. P.M. Mountziaris, A.G. Mikos, Modulation of the inflammatory response for enhanced bone tissue regeneration. Tissue Eng. Part B Rev. 14, 179 (2008)

10. T.J. Keane, S.F. Badylak, in (Elsevier, 2014), pp. 112-118

11. C. Patra, S. Talukdar, T. Novoyatleva, S.R. Velagala, C. Mühlfeld, B. Kundu, S.C. Kundu, F.B. Engel, Silk protein fibroin from Antheraea mylitta for cardiac tissue engineering. Biomaterials 33, 2673 (2012)

12. A.R. Murphy, D.L. Kaplan, Biomedical applications of chemically-modified silk fibroin. J. Mater. Chem. 19, 6443 (2009)

13. I. Dal Pra, G. Freddi, J. Minic, A. Chiarini, U. Armato, De novo engineering of reticular connective tissue in vivo by silk fibroin nonwoven materials. Biomaterials 26, 1987 (2005)

14. R.E. Unger, M. Wolf, K. Peters, A. Motta, C. Migliaresi, C.J. Kirkpatrick, Growth of human cells on a non-woven silk fibroin net: a potential for use in tissue engineering. Biomaterials 25, 1069 (2004)

15. A. Teimouri, M. Azadi, R. Emadi, J. Lari, A.N. Chermahini, Preparation, characterization, degradation and biocompatibility of different silk fibroin based composite scaffolds prepared by freeze-drying method for tissue engineering application. Polym. Degrad. Stab. 121, 18 (2015)

16. H. Liu, X. Li, G. Zhou, H. Fan, Y. Fan, Electrospun sulfated silk fibroin nanofibrous scaffolds for vascular tissue engineering. Biomaterials 32, 3784 (2011)

17. L. Wei, S. Wu, M. Kuss, X. Jiang, R. Sun, P. Reid, X. Qin, B. Duan, 3D printing of silk fibroin-based hybrid scaffold treated with platelet rich plasma for bone tissue engineering. Bioact. Mater. 4, 256 (2019)

18. C.M. Srivastava, R. Purwar, A.P. Gupta, Enhanced potential of biomimetic, silver nanoparticles functionalized Antheraea mylitta (tasar) silk fibroin nanofibrous mats for skin tissue engineering. Int. J. Biol. Macromol. 130, $437(2019)$

19. M. Xie, Y. Xu, L. Song, J. Wang, X. Lv, Y. Zhang, Tissue-engineered buccal mucosa using silk fibroin matrices for urethral reconstruction in a canine model. J. Surg. Res. 188, 1 (2014)

20. S. Suzuki, A.M. Shadforth, S. McLenachan, D. Zhang, S.-C. Chen, J. Walshe, G.E. Lidgerwood, A. Pébay, T.V. Chirila, F.K. Chen, Optimization of silk fibroin membranes for retinal implantation. Mater. Sci. Eng. C 105, 110131 (2019)
21. B. Marelli, A. Alessandrino, S. Farè, G. Freddi, D. Mantovani, M.C. Tanzi, Compliant electrospun silk fibroin tubes for small vessel bypass grafting. Acta Biomater. 6, 4019 (2010)

22. B. Singh, K. Pramanik, Fabrication and evaluation of non-mulberry silk fibroin fiber reinforced chitosan based porous composite scaffold for cartilage tissue engineering. Tissue Cell 55, 83 (2018)

23. M. Garcia-Fuentes, A.J. Meinel, M. Hilbe, L. Meinel, H.P. Merkle, Silk fibroin/ hyaluronan scaffolds for human mesenchymal stem cell culture in tissue engineering. Biomaterials 30, 5068 (2009)

24. F. Croisier, C. Jérôme, Chitosan-based biomaterials for tissue engineering. Eur. Polym. J. 49, 780 (2013)

25. S. Ahmed, S. Ikram, Chitosan based scaffolds and their applications in wound healing. Achiev. Life Sci. 10, 27 (2016)

26. L. Hu, Y. Sun, Y. Wu, Advances in chitosan-based drug delivery vehicles. Nanoscale 5, 3103 (2013)

27. R. LogithKumar, A. KeshavNarayan, S. Dhivya, A. Chawla, S. Saravanan, N. Selvamurugan, A review of chitosan and its derivatives in bone tissue engineering. Carbohydr. Polym. 151, 172 (2016)

28. C. Laurencin, M. Deng, Natural and Synthetic Biomedical Polymers (Newnes, 2014)

29. L.L. Reys, S.S. Silva, R.P. Pirraco, A.P. Marques, J.F. Mano, T.H. Silva, R.L. Reis, Influence of freezing temperature and deacetylation degree on the performance of freeze-dried chitosan scaffolds towards cartilage tissue engineering. Eur. Polym. J. 95, 232 (2017)

30. T. Vieira, J.C. Silva, A.B. do Rego, J.P. Borges, C. Henriques, Electrospun biodegradable chitosan based-poly (urethane urea) scaffolds for soft tissue engineering. Mater. Sci. Eng. C 103, 109819 (2019)

31. N.M. Ergul, S. Unal, I. Kartal, C. Kalkandelen, N. Ekren, O. Kilic, L. ChiChang, 0. Gunduz, 3D printing of chitosan/poly (vinyl alcohol) hydrogel containing synthesized hydroxyapatite scaffolds for hard-tissue engineering. Polym. Test. 79, 106006 (2019)

32. T. Kutlusoy, B. Oktay, N.K. Apohan, M. Süleymanoğlu, S.E. Kuruca, Chitosan-co-hyaluronic acid porous cryogels and their application in tissue engineering. Int. J. Biol. Macromol. 103, 366 (2017)

33. K. Saekhor, W. Udomsinprasert, S. Honsawek, W. Tachaboonyakiat, Preparation of an injectable modified chitosan-based hydrogel approaching for bone tissue engineering. Int. J. Biol. Macromol. 123, 167 (2019)

34. A.K. Demir, A.E. Elçin, Y.M. Elçin, Strontium-modified chitosan/montmorilIonite composites as bone tissue engineering scaffold. Mater. Sci. Eng. C 89, 8 (2018)

35. N. Li, L. Zhou, W. Xie, D. Zeng, D. Cai, H. Wang, C. Zhou, J. Wang, L. Li, Alkaline phosphatase enzyme-induced biomineralization of chitosan scaffolds with enhanced osteogenesis for bone tissue engineering. Chem. Eng. J. 371, 618 (2019)

36. K. Kalishwaralal, S. Jeyabharathi, K. Sundar, S. Selvamani, M. Prasanna, A. Muthukumaran, A novel biocompatible chitosan-selenium nanoparticles (SeNPs) film with electrical conductivity for cardiac tissue engineering application. Mater. Sci. Eng. C 92, 151 (2018)

37. J. Zhang, D. Wang, X. Jiang, L. He, L. Fu, Y. Zhao, Y. Wang, H. Mo, J. Shen, Multistructured vascular patches constructed via layer-by-layer selfassembly of heparin and chitosan for vascular tissue engineering applications. Chem. Eng. J. 370, 1057 (2019)

38. Y. Zhou, D. Yang, X. Chen, Q. Xu, F. Lu, J. Nie, Electrospun water-soluble carboxyethyl chitosan/poly (vinyl alcohol) nanofibrous membrane as potential wound dressing for skin regeneration. Biomacromo/9, 349 (2008)

39. A. Sadeghi, F. Moztarzadeh, J.A. Mohandesi, Investigating the effect of chitosan on hydrophilicity and bioactivity of conductive electrospun composite scaffold for neural tissue engineering. Int. J. Biol. Macromol. 121, 625 (2019)

40. C. Al Christopher, Í.G. Silva, K.D. Pangilinan, Q. Chen, E.B. Caldona, R.C. Advincula, High performance polymers for oil and gas applications. React. Funct. Polym. 162, 104878 (2021)

41. C.-W. Lou, C.-H. Yao, Y.-S. Chen, T.-C. Hsieh, J.-H. Lin, W.-H. Hsing, Manufacturing and properties of PLA absorbable surgical suture. Text. Res. J. 78, 958 (2008)

42. A. Heino, A. Naukkarinen, T. Kulju, P. Törmälä, T. Pohjonen, E. Mäkelä, Characteristics of poly $(L-)$ lactic acid suture applied to fascial closure in rats. $J$. Biomed. Mater. Res. Off. J. Soc. Biomater. Jpn. Soc. Biomater. 30, 187 (1996) 
43. H. Xia, X. Gao, G. Gu, Z. Liu, Q. Hu, Y. Tu, Q. Song, L. Yao, Z. Pang, X. Jiang, Penetratin-functionalized PEG-PLA nanoparticles for brain drug delivery. Int. J. Pharm. 436, 840 (2012)

44. D. Howard, K. Partridge, X. Yang, N.M. Clarke, Y. Okubo, K. Bessho, S.M. Howdle, K.M. Shakesheff, R.O. Oreffo, Immunoselection and adenoviral genetic modulation of human osteoprogenitors: in vivo bone formation on PLA scaffold. Biochem. Biophys. Res. Commun. 299, 208 (2002)

45. S. Shao, S. Zhou, L. Li, J. Li, C. Luo, J. Wang, X. Li, J. Weng, Osteoblast function on electrically conductive electrospun PLA/MWCNTs nanofibers. Biomaterials 32, 2821 (2011)

46. L.K. Narayanan, P. Huebner, M.B. Fisher, J.T. Spang, B. Starly, R.A. Shirwaiker, 3D-bioprinting of polylactic acid (PLA) nanofiber-alginate hydrogel bioink containing human adipose-derived stem cells. ACS Biomater. Sci. Eng. 2, 1732 (2016)

47. F. Diomede, A. Gugliandolo, P. Cardelli, I. Merciaro, V. Ettorre, T. Traini, R. Bedini, D. Scionti, A. Bramanti, A. Nanci, Three-dimensional printed PLA scaffold and human gingival stem cell-derived extracellular vesicles: a new tool for bone defect repair. Stem Cell Res. Ther. 9, 104 (2018)

48. A. Gugliandolo, F. Diomede, P. Cardelli, A. Bramanti, D. Scionti, P. Bramanti, 0 . Trubiani, E. Mazzon, Transcriptomic analysis of gingival mesenchymal stem cells cultured on $3 \mathrm{~d}$ bioprinted scaffold: a promising strategy for neuroregeneration. J. Biomed. Mater. Res. A 106, 126 (2018)

49. A.C. Daly, L. Riley, T. Segura, J.A. Burdick, Hydrogel microparticles for biomedical applications. Nat. Rev. Mater. 5, 20 (2020)

50. B.P. Panda, R. Krishnamoorthy, S.K. Bhattamisra, N.K.H. Shivashekaregowda, L.B. Seng, S. Patnaik, Fabrication of second generation smarter PLGA based nanocrystal carriers for improvement of drug delivery and therapeutic efficacy of gliclazide in type-2 diabetes rat model. Sci. Rep. $\mathbf{9}$, 1 (2019)

51. P. Liu, W. Chen, C. Liu, M. Tian, P. Liu, A novel poly (vinyl alcohol)/poly (ethylene glycol) scaffold for tissue engineering with a unique bimodal open-celled structure fabricated using supercritical fluid foaming. Sci. Rep. 9, 1 (2019)

52. K.M. Kovach, J.R. Capadona, A.S. Gupta, J.A. Potkay, The effects of PEGbased surface modification of PDMS microchannels on long-term hemocompatibility. J. Biomed. Mater. Res. A 102, 4195 (2014)

53. J.M. Harris, Poly (Ethylene Glycol) Chemistry: Biotechnical and Biomedical Applications (Springer, Berlin, 1992).

54. V. Truong, I. Blakey, A.K. Whittaker, Hydrophilic and amphiphilic polyethylene glycol-based hydrogels with tunable degradability prepared by "click" chemistry. Biomacromol 13, 4012 (2012)

55. G. Gao, T. Yonezawa, K. Hubbell, G. Dai, X. Cui, Inkjet-bioprinted acrylated peptides and PEG hydrogel with human mesenchymal stem cells promote robust bone and cartilage formation with minimal printhead clogging. Biotechnol. J. 10, 1568 (2015)

56. W. Zhang, B. Chen, H. Zhao, P. Yu, D. Fu, J. Wen, X. Peng, Processing and characterization of supercritical $\mathrm{CO}_{2}$ batch foamed poly(lactic acid)/ poly(ethylene glycol) scaffold for tissue engineering application. J. Appl. Polym. Sci. 130, 3066 (2013)

57. K. Remya, J. Joseph, S. Mani, A. John, H. Varma, P. Ramesh, Nanohydroxyapatite incorporated electrospun polycaprolactone/polycaprolactone-polyethyleneglycol-polycaprolactone blend scaffold for bone tissue engineering applications. J. Biomed. Nanotechnol. 9, 1483 (2013)

58. G. Ma, D. Yang, Q. Li, K. Wang, B. Chen, J.F. Kennedy, J. Nie, Injectable hydrogels based on chitosan derivative/polyethylene glycol dimethacrylate $/ N, N$-dimethylacrylamide as bone tissue engineering matrix. Carbohydr. Polym. 79, 620 (2010)

59. J.-L. Ruan, N.L. Tulloch, V. Muskheli, E.E. Genova, P.D. Mariner, K.S. Anseth, C.E. Murry, An improved cryosection method for polyethylene glycol hydrogels used in tissue engineering. Tissue Eng. Part C Methods 19, 794 (2013)

60. A.K. Blakney, M.D. Swartzlander, S.J. Bryant, The effects of substrate stiffness on the in vitro activation of macrophages and in vivo host response to poly(ethylene glycol)-based hydrogels. J. Biomed. Mater. Res. A 100, 1375 (2012)

61. J.J. Roberts, S.J. Bryant, Comparison of photopolymerizable thiol-ene PEG and acrylate-based PEG hydrogels for cartilage development. Biomaterials 34, 9969 (2013)

62. M. Shakir, R. Jolly, M.S. Khan, N. Iram, T.K. Sharma, S.I. Al-Resayes, Synthesis and characterization of a nano-hydroxyapatite/chitosan/polyethylene glycol nanocomposite for bone tissue engineering. Polym. Adv. Technol. 26, 41 (2015)

63. F. Tan, X. Xu, T. Deng, M. Yin, X. Zhang, J. Wang, Fabrication of positively charged poly(ethylene glycol)-diacrylate hydrogel as a bone tissue engineering scaffold. Biomed. Mater. 7, 055009 (2012)

64. S. Shinohara, T. Kihara, S. Sakai, M. Matsusaki, M. Akashi, M. Taya, J. Miyake, Fabrication of in vitro three-dimensional multilayered blood vessel model using human endothelial and smooth muscle cells and highstrength PEG hydrogel. J. Biosci. Bioeng. 116, 231 (2013)

65. X. Zhang, B. Xu, D.S. Puperi, A.L. Yonezawa, Y. Wu, H. Tseng, M.L. Cuchiara, J.L. West, K.J. Grande-Allen, Integrating valve-inspired design features into poly(ethylene glycol) hydrogel scaffolds for heart valve tissue engineering. Acta Biomater. 14, 11 (2015)

66. G. Parker, Encyclopedia of materials: science and technology (2001)

67. M.R. Ladd, S.J. Lee, J.D. Stitzel, A. Atala, J.J. Yoo, Co-electrospun dual scaffolding system with potential for muscle-tendon junction tissue engineering. Biomaterials 32, 1549 (2011)

68. H. Abdo, A. Elzatahry, H. Alharbi, K. Khalil, in Biopolym. Compos. Electron. (Elsevier, 2017), pp. 13-25

69. T. Patrício, M. Domingos, A. Gloria, U. D’Amora, J. Coelho, P. Bártolo, Fabrication and characterisation of PCL and PCL/PLA scaffolds for tissue engineering. Rapid Prototyp. J. 20, 145 (2014)

70. H. Xu, W. Cui, J. Chang, Fabrication of patterned PDLLA/PCL composite scaffold by electrospinning. J. Appl. Polym. Sci. 127, 1550 (2013)

71. M. Domingos, F. Intranuovo, T. Russo, R. De Santis, A. Gloria, L. Ambrosio, J. Ciurana, P. Bartolo, The first systematic analysis of 3D rapid prototyped poly ( $\varepsilon$-caprolactone) scaffolds manufactured through BioCell printing: the effect of pore size and geometry on compressive mechanical behaviour and in vitro hMSC viability. Biofabrication 5, 045004 (2013)

72. A.K. Ekaputra, Y. Zhou, S.M. Cool, D.W. Hutmacher, Composite electrospun scaffolds for engineering tubular bone grafts. Tissue Eng. Part A 15, 3779 (2009)

73. J. Han, P. Lazarovici, C. Pomerantz, X. Chen, Y. Wei, P.I. Lelkes, Co-electrospun blends of PLGA, gelatin, and elastin as potential nonthrombogenic scaffolds for vascular tissue engineering. Biomacromol 12, 399 (2011)

74. A. Subramanian, U.M. Krishnan, S. Sethuraman, Fabrication, characterization and in vitro evaluation of aligned PLGA-PCL nanofibers for neural regeneration. Ann. Biomed. Eng. 40, 2098 (2012)

75. J.-F. Lutz, H.G. Börner, Modern trends in polymer bioconjugates design. Prog. Polym. Sci. 33, 1 (2008)

76. C. Chen, D.Y.W. Ng, T. Weil, Polymer bioconjugates: modern design concepts toward precision hybrid materials. Prog. Polym. Sci. 105, 101241 (2020)

77. J.Z. Manapat, Q. Chen, P. Ye, R.C. Advincula, 3D printing of polymer nanocomposites via stereolithography. Macromol. Mater. Eng. 302, 1600553 (2017)

78. G. Taormina, C. Sciancalepore, M. Messori, F. Bondioli, 3D printing processes for photocurable polymeric materials: technologies, materials, and future trends. J. Appl. Biomater. Funct. Mater. 16, 151 (2018)

79. V.S. Voet, T. Strating, G.H. Schnelting, P. Dijkstra, M. Tietema, J. Xu, A.J. Woortman, K. Loos, J. Jager, R. Folkersma, Biobased acrylate photocurable resin formulation for stereolithography 3D printing. ACS Omega 3, 1403 (2018)

80. G. Salmoria, C. Ahrens, V. Beal, A. Pires, V. Soldi, Evaluation of post-curing and laser manufacturing parameters on the properties of SOMOS 7110 photosensitive resin used in stereolithography. Mater. Des. 30, 758 (2009)

81. A.C. Uzcategui, A. Muralidharan, V.L. Ferguson, S.J. Bryant, R.R. McLeod, Understanding and improving mechanical properties in 3D printed parts using a dual-cure acrylate-based resin for stereolithography. Adv. Eng. Mater. 20, 1800876 (2018)

82. C. Gorsche, K. Seidler, P. Knaack, P. Dorfinger, T. Koch, J. Stampfl, N. Moszner, R. Liska, Rapid formation of regulated methacrylate networks yielding tough materials for lithography-based 3D printing. Polym. Chem. 7, 2009 (2016)

83. F.P. Melchels, J. Feijen, D.W. Grijpma, A review on stereolithography and its applications in biomedical engineering. Biomaterials 31, 6121 (2010)

84. J. Palaganas, A.C. de Leon, J. Mangadlao, N. Palaganas, A. Mael, Y.J. Lee, H.Y. Lai, R. Advincula, Facile preparation of photocurable siloxane composite for 3D printing. Macromol. Mater. Eng. 302, 1600477 (2017) 
85. K. Arcaute, B.K. Mann, R.B. Wicker, Stereolithography of three-dimensional bioactive poly (ethylene glycol) constructs with encapsulated cells. Ann. Biomed. Eng. 34, 1429 (2006)

86. S. Miao, W. Zhu, N.J. Castro, M. Nowicki, X. Zhou, H. Cui, J.P. Fisher, L.G. Zhang, 4D printing smart biomedical scaffolds with novel soybean oil epoxidized acrylate. Sci. Rep. 6, 1 (2016)

87. N.J. Castro, J. O'brien, L.G. Zhang, Integrating biologically inspired nanomaterials and table-top stereolithography for 3D printed biomimetic osteochondral scaffolds. Nanoscale 7, 14010 (2015)

88. A. Hoffmann, H. Leonards, N. Tobies, L. Pongratz, K. Kreuels, F. Kreimendahl, C. Apel, M. Wehner, N. Nottrodt, New stereolithographic resin providing functional surfaces for biocompatible three-dimensional printing. $J$. Tissue Eng. 8, 2041731417744485 (2017)

89. I.A. Barker, M.P. Ablett, H.T. Gilbert, S.J. Leigh, J.A. Covington, J.A. Hoyland, S.M. Richardson, A.P. Dove, A microstereolithography resin based on thiol-ene chemistry: towards biocompatible 3D extracellular constructs for tissue engineering. Biomater. Sci. 2, 472 (2014)

90. M.E. Alemán-Domínguez, E. Giusto, Z. Ortega, M. Tamaddon, A.N. Benítez, C. Liu, Three-dimensional printed polycaprolactone-microcrystalline cellulose scaffolds. J. Biomed. Mater. B Res. Appl. Biomater. 107, 521 (2019)

91. D. Liu, W. Nie, D. Li, W. Wang, L. Zheng, J. Zhang, J. Zhang, C. Peng, X. Mo, C. He, 3D printed PCL/SrHA scaffold for enhanced bone regeneration. Chem. Eng. J. 362, 269 (2019)

92. L. Li, J. Li, J. Guo, H. Zhang, X. Zhang, C. Yin, L. Wang, Y. Zhu, Q. Yao, 3D molecularly functionalized cell-free biomimetic scaffolds for osteochondral regeneration. Adv. Funct. Mater. 29, 1807356 (2019)

93. M. Rasoulianboroujeni, F. Fahimipour, P. Shah, K. Khoshroo, M. Tahriri, H. Eslami, A. Yadegari, E. Dashtimoghadam, L. Tayebi, Development of 3D-printed PLGA/TiO ${ }_{2}$ nanocomposite scaffolds for bone tissue engineering applications. Mater. Sci. Eng. C 96, 105 (2019)

94. Y. Lai, Y. Li, H. Cao, J. Long, X. Wang, L. Li, C. Li, Q. Jia, B. Teng, T. Tang, Osteogenic magnesium incorporated into PLGA/TCP porous scaffold by 3D printing for repairing challenging bone defect. Biomaterials 197, 207 (2019)

95. J. Liu, L. Li, H. Suo, M. Yan, J. Yin, J. Fu, 3D printing of biomimetic multilayered GelMA/nHA scaffold for osteochondral defect repair. Mater. Des. 171, 107708 (2019)

96. W. Xu, B.Z. Molino, F. Cheng, P.J. Molino, Z. Yue, D. Su, X. Wang, S. Willför, C. $\mathrm{Xu}, \mathrm{G}$.G. Wallace, On low-concentration inks formulated by nanocellulose assisted with gelatin methacrylate (GeIMA) for 3D printing toward wound healing application. ACS Appl. Mater. Interfaces 11, 8838 (2019)

97. Z. Lin, M. Wu, H. He, Q. Liang, C. Hu, Z. Zeng, D. Cheng, G. Wang, D. Chen, H. Pan, 3D printing of mechanically stable calcium-free alginate-based scaffolds with tunable surface charge to enable cell adhesion and facile biofunctionalization. Adv. Funct. Mater. 29, 1808439 (2019)

98. G. Luo, Y. Ma, X. Cui, L. Jiang, M. Wu, Y. Hu, Y. Luo, H. Pan, C. Ruan, 13-93 bioactive glass/alginate composite scaffolds $3 \mathrm{D}$ printed under mild conditions for bone regeneration. RSC Adv. 7, 11880 (2017)

99. G. Salmoria, J. Leite, R. Paggi, A. Lago, A. Pires, Selective laser sintering of PA12/HDPE blends: effsect of components on elastic/plastic behavior. Polym. Test. 27, 654 (2008)

100. J. Yang, Y. Shi, C. Yan, Selective laser sintering of polyamide 12/potassium titanium whisker composites. J. Appl. Polym. Sci. 117, 2196 (2010)

101. C. Zhu, T. Liu, F. Qian, W. Chen, S. Chandrasekaran, B. Yao, Y. Song, E.B. Duoss, J.D. Kuntz, C.M. Spadaccini, 3D printed functional nanomaterials for electrochemical energy storage. Nano Today 15, 107 (2017)

102. T. Kumaresan, R. Gandhinathan, M. Ramu, M. Ananthasubramanian, K.B. Pradheepa, Design, analysis and fabrication of polyamide/hydroxyapatite porous structured scaffold using selective laser sintering method for biomedical applications. J. Mech. Sci. Technol. 30, 5305 (2016)

103. Y. Zhang, L. Hao, M. Savalani, R.A. Harris, L. DiSilvio, K. Tanner, In vitro biocompatibility of hydroxyapatite-reinforced polymeric composites manufactured by selective laser sintering. J. Biomed. Mater. Res. Part Off. J. Soc. Biomater. Jpn. Soc. Biomater. Aust. Soc. Biomater. Korean Soc. Biomater. 91, 1018 (2009)

104. J.M. Williams, A. Adewunmi, R.M. Schek, C.L. Flanagan, P.H. Krebsbach, S.E. Feinberg, S.J. Hollister, S. Das, Bone tissue engineering using polycaprolactone scaffolds fabricated via selective laser sintering. Biomaterials 26, 4817 (2005)

105. K. Tan, C. Chua, K. Leong, C. Cheah, P. Cheang, M.A. Bakar, S. Cha, Scaffold development using selective laser sintering of polyetheretherketonehydroxyapatite biocomposite blends. Biomaterials 24, 3115 (2003)

106. R.L. Simpson, F.E. Wiria, A.A. Amis, C.K. Chua, K.F. Leong, U.N. Hansen, M. Chandrasekaran, M.W. Lee, Development of a $95 / 5$ poly (L-lactide-Coglycolide)/hydroxylapatite and $\beta$-tricalcium phosphate scaffold as bone replacement material via selective laser sintering. J. Biomed. Mater. Res. B Appl. Biomater. 84, 17 (2008)

107. W. Yeong, N. Sudarmadji, H. Yu, C. Chua, K. Leong, S. Venkatraman, Y. Boey, L. Tan, Porous polycaprolactone scaffold for cardiac tissue engineering fabricated by selective laser sintering. Acta Biomater. 6, 2028 (2010)

108. I. Shishkovskii, I. Yadroitsev, I.Y. Smurov, Selective laser sintering/melting of nitinol-hydroxyapatite composite for medical applications. Powder Metall. Met. Ceram. 50, 275 (2011)

109. J.-P. Fouassier, J. Lalevï, Photoinitiators for Polymer Synthesis: Scope, Reactivity, and Efficiency (Wiley, 2012)

110. A. Javadi, H.S. Mehr, M. Sobani, M.D. Soucek, Cure-on-command technology: a review of the current state of the art. Prog. Org. Coat. 100, 2 (2016)

111. B.C. Gross, J.L. Erkal, S.Y. Lockwood, C. Chen, D.M. Spence, Evaluation of $3 \mathrm{D}$ printing and its potential impact on biotechnology and the chemical sciences. (2014)

112. C. Decker, C. Bianchi, S. Jönsson, Light-induced crosslinking polymerization of a novel N-substituted bis-maleimide monomer. Polymer 45, 5803 (2004)

113. N. Davidenko, J. Campbell, E. Thian, C. Watson, R. Cameron, Collagenhyaluronic acid scaffolds for adipose tissue engineering. Acta Biomater. 6, $3957(2010)$

114. C.N. Grover, R.E. Cameron, S.M. Best, Investigating the morphological, mechanical and degradation properties of scaffolds comprising collagen, gelatin and elastin for use in soft tissue engineering. J. Mech. Behav. Biomed. Mater. 10, 62 (2012)

115. W. Schuurman, P.A. Levett, M.W. Pot, P.R. van Weeren, W.J. Dhert, D.W. Hutmacher, F.P. Melchels, T.J. Klein, J. Malda, Gelatin-methacrylamide hydrogels as potential biomaterials for fabrication of tissue-engineered cartilage constructs. Macromol. Biosci. 13, 551 (2013)

116. A.I. Van Den Bulcke, B. Bogdanov, N. De Rooze, E.H. Schacht, M. Cornelissen, H. Berghmans, Structural and rheological properties of methacrylamide modified gelatin hydrogels. Biomacromol 1, 31 (2000)

117. T. Billiet, E. Gevaert, T. De Schryver, M. Cornelissen, P. Dubruel, The 3D printing of gelatin methacrylamide cell-laden tissue-engineered constructs with high cell viability. Biomaterials 35, 49 (2014)

118. Z. Wicks, F. Jones, S. Pappas, D. Wicks, Radiation cure coatings. Org. Coat 574 (2006).

119. H. Hageman, Photoinitiators for free radical polymerization. Prog. Org. Coat. 13, $123(1985)$

120. Y.-C. Lai, E.T. Quinn, in (ACS Publications, 1997)

121. S.J. Bryant, C.R. Nuttelman, K.S. Anseth, Cytocompatibility of UV and visible light photoinitiating systems on cultured $\mathrm{NIH} / 3 \mathrm{~T} 3$ fibroblasts in vitro. J. Biomater. Sci. Polym. Ed. 11, 439 (2000)

122. C.G. Williams, A.N. Malik, T.K. Kim, P.N. Manson, J.H. Elisseeff, Variable cytocompatibility of six cell lines with photoinitiators used for polymerizing hydrogels and cell encapsulation. Biomaterials 26, 1211 (2005)

123. C.P. Ramil, Q. Lin, Photoclick chemistry: a fluorogenic light-triggered in vivo ligation reaction. Curr. Opin. Chem. Biol. 21, 89 (2014)

124. Y. Fan, C. Deng, R. Cheng, F. Meng, Z. Zhong, In situ forming hydrogels via catalyst-free and bioorthogonal "tetrazole-alkene" photo-click chemistry. Biomacromol 14, 2814 (2013)

125. F. Aloui, A. Ahajji, Y. Irmouli, B. George, B. Charrier, A. Merlin, Inorganic UV absorbers for the photostabilisation of wood-clearcoating systems: comparison with organic UV absorbers. Appl. Surf. Sci. 253, 3737 (2007)

126. N.E. Zander, M. Gillan, R.H. Lambeth, Recycled polyethylene terephthalate as a new FFF feedstock material. Addit. Manuf. 21, 174 (2018)

127. D.A. Gordon, Z. Zhan, L.S. Bruckman, Characterizing the weathering induced degradation of poly (ethylene-terephthalate) using PARAFAC modeling of fluorescence spectra. Polym. Degrad. Stab. 161, 85 (2019) 
128. Z. Huang, A. Ding, H. Guo, G. Lu, X. Huang, Construction of nontoxic polymeric UV-absorber with great resistance to UV-photoaging. Sci. Rep. 6, 1 (2016)

129. A. Natansohn, P. Rochon, Photoinduced motions in azo-containing polymers. Chem. Rev. 102, 4139 (2002)

130. T.F. Scott, A.D. Schneider, W.D. Cook, C.N. Bowman, Photoinduced plasticity in cross-linked polymers. Science 308, 1615 (2005)

131. I.A. Marozas, J.J. Cooper-White, K.S. Anseth, Photo-induced viscoelasticity in cytocompatible hydrogel substrates. New J. Phys. 21, 045004 (2019)

132. M.E. Hake, H. Young, D.J. Hak, P.F. Stahel, E.M. Hammerberg, C. Mauffrey, Local antibiotic therapy strategies in orthopaedic trauma: practical tips and tricks and review of the literature. Injury 46, 1447 (2015)

133. D.K. Mills, U. Jammalamadaka, K. Tappa, J. Weisman, Studies on the cytocompatibility, mechanical and antimicrobial properties of 3D printed poly(methyl methacrylate) beads. Bioact. Mater. 3, 157 (2018)

134. A. Francis, R. Detsch, A. Boccaccini, Fabrication and cytotoxicity assessment of novel polysiloxane/bioactive glass films for biomedical applications. Ceram. Int. 42, 15442 (2016)
135. D.J. Whyte, R. Rajkhowa, B. Allardyce, A.Z. Kouzani, A review on the challenges of 3D printing of organic powders. Bioprinting 16, e00057 (2019)

136. K. Hölzl, S. Lin, L. Tytgat, S. Van Vlierberghe, L. Gu, A. Ovsianikov, Bioink properties before, during and after 3D bioprinting. Biofabrication 8, 032002 (2016)

137. Y.-J. Choi, J.H. Park, J. Jang, D.-W. Cho, 3D bioprinting technologies and bioinks for therapeutic and tissue engineering applications. J. 3D Print. Med. 2, 187 (2018)

138. J. Liu, S. Willför, A. Mihranyan, On importance of impurities, potential leachables and extractables in algal nanocellulose for biomedical use. Carbohydr. Polym. 172, 11 (2017)

139. S. Gad: in Charact. Biomater. (Elsevier, 2013), pp. 285-306

140. P. de O.M.D. Batista, A.M. Lopes, P.G. Mazzola, C. de O.R. Yagui, T.C.V. Penna, A. Pessoa Júnior, Methods of endotoxin removal from biological preparations: a review (2007)

141. Y. Yang, S. Yang, Y. Wang, Z. Yu, H. Ao, H. Zhang, L. Qin, O. Guillaume, D. Eglin, R.G. Richards, Anti-infective efficacy, cytocompatibility and biocompatibility of a 3D-printed osteoconductive composite scaffold functionalized with quaternized chitosan. Acta Biomater. 46, 112 (2016) 